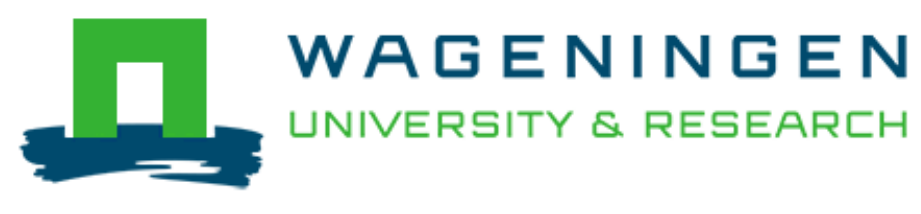

\author{
Obstacles and features of Farm Management Information Systems: A \\ systematic literature review \\ Tummers, J., Kassahun, A., \& Tekinerdogan, B.
}

This is a "Post-Print" accepted manuscript, which has been published in "Computers and Electronics in Agriculture"

This version is distributed under a non-commercial no derivatives Creative Commons (c) (1) (9) (CC-BY-NC-ND) user license, which permits use, distribution, and reproduction in any medium, provided the original work is properly cited and not used for commercial purposes. Further, the restriction applies that if you remix, transform, or build upon the material, you may not distribute the modified material.

Please cite this publication as follows:

Tummers, J., Kassahun, A., \& Tekinerdogan, B. (2019). Obstacles and features of Farm Management Information Systems: A systematic literature review. Computers and Electronics in Agriculture, 157, 189-204. DOI: 10.1016/j.compag.2018.12.044

You can download the published version at:

https://doi.org/10.1016/j.compag.2018.12.044 


\title{
Obstacles and Features of Farm Management Information Systems: A Systematic Literature Review
}

\author{
J. Tummers ${ }^{\mathrm{a}}$, A. Kassahun ${ }^{\mathrm{a}}$, B. Tekinerdogan ${ }^{\mathrm{a}, *}$ \\ a Information Technology Group, Wageningen University $\&$ Research, Hollandseweg 1, 6706 KN Wageningen, The Netherlands
}

\begin{abstract}
Various Farm Management Information Systems (FMISs) have been developed to support the management of the farm businesses. These FMISs typically support the different domains of the agricultural sector, such as arable and dairy farming; and include different set of features, such as crop, field, and financial management. These FMISs also have to deal with diverse obstacles during their development and adoption, such as lack of standardized data, cost and usability. Though several papers have been published in the past several years on this topic, there has been no explicit attempt to systematically review these papers to identify and characterize the features and obstacles. The objective of this study is to identify and describe the state-of-the-art of FMISs and as such pave the way for further research and development of FMISs. We applied a systematic literature review protocol in which we included the literature published from 2008 to 2018. We found 1048 papers of which 38 papers were selected as primary studies that we analyzed further in detail. From the detailed analysis, we identified 81 unique FMIS features and 51 unique obstacles of FMISs. We have systematically ranked the identified features and obstacles and describe the key associated aspects. These aspects include the agricultural domains, modeling approaches, delivery models, and identified stakeholders.
\end{abstract}

Keywords: Farm Management Information System; systematic literature review; features of FMIS; obstacles to FMIS

\section{Introduction}

A Farm Management Information System (FMIS) or, in short, a Farm Management System (FMS) is developed to support the management of diverse farm enterprises. An FMIS is essentially a Management Information System (MIS) for the agriculture sector. According to Waston et al. (1987) 1] an MIS is defined as: "an organizational method of providing past, present and projected information related to internal operations and external intelligence." An MIS supports decision making by providing timely information about the planning, control and operational functions of an organization [1. By the same token, an FMIS supports timely decision making within farm enterprises. Over the years MISs for agriculture have developed from simple farm data recording systems into

\footnotetext{
${ }^{*}$ Corresponding author

Email address: bedir.tekinerdogan@wur.nl (B. Tekinerdogan )
} 
extensive FMISs [2]. Sørensen et al. (2010) 3] defines an FMIS as: "a planned system for the collecting, processing, storing and disseminating of data in the form of information needed to carry out the operations functions of the farm." FMISs can support decision making by finding the best practices for farm management [2]. The main purpose of current FMISs is to reduce the production costs, maintain high product quality and safety, and to comply with agricultural standards 2. In general, an FMIS supports decision making and helps with keeping track of the current business processes to maximize the profit of a farm.

To understand FMISs, it is important to know which features they support, which obstacles are encountered in developing and using FMISs, and the context in which the FMISs are used. In this paper, we define features of an FMIS as user-visible characteristics. All features together constitute to what we refer as an FMIS. Widely supported features of FMISs include Feed management, Financial management, and Labour management [4. Developers of FMISs face many obstacles in providing the desired FMIS features. Likewise, a substandard FMIS creates a number of obstacles for end users. In this study, we regard an obstacle in general terms as any problem related to the development or the use of FMISs. Since the adoption of FMISs is directly related not only to the features provided but also to the obstacles faced, an SLR of FMISs also needs to consider studies that identify and describe the current obstacles and open issues of FMISs.

It turns out that different FMISs are offered to different domains of the agricultural sector. For instance, while some FMISs focus on arable farming, others concentrate on livestock farming. Different FMISs have different licensing and delivery models. They can for example run on mobile phones or desktop computers and can be commercial or non-commercial. FMISs can be described using formal software architecture models. These models address specific concerns of the stakeholders of the system [5]. In order to describe FMISs, it is also important to identify the stakeholders and which features are of value to them.

In the past years, FMISs have been considered in multiple studies. There is, however, no structured information about what constitutes as an FMIS and which features it can support. FMISs have been considered from different perspectives, but no clear and consistent set of features of FMISs has been defined so far. Identifying and describing the features and obstacles is essential for both the practitioners who aim to build FMISs and researchers who study FMISs. In this paper, we provide a systematic literature review (SLR) to address these issues. The goal of this SLR is to identify all FMISs described in the scientific literature and their common obstacles and features. For carrying out the SLR, we have adopted the protocol as defined by Kitchenham et al. (2009) [6]. In this research, the SLR is performed to identify all prior research about FMISs and to give a reliable and extensive review of all preliminary research.

The remainder of the paper is organized as follows. Section 2 shows the related work. Section 3 describes our 40 review protocol in detail. Section 4 presents the results of the SLR. Section 5 presents the discussion and finally Section 6 concludes the paper. 


\section{Related work}

In this section, we describe the limited review literature on FMIS that we were able to find. To our best effort we were unable to find a systematic literature review on FMISs, and in this respect, the present study represents a pioneering effort that paves the way for systematically reviewing the state-of-the-art knowledge on FMISs. Particularly, we were able to find three closely related scientific papers and one professional publication which we describe below, together with other relevant literature.

Fountas et al. 2] evaluates current FMIS designs and solutions and describes the current situation and future perspectives. They present the state-of-the-art of FMIS applications in 2015, in order to provide a basis for future FMISs. They found a total of 141 different commercial FMISs, coming from 75 software vendors. From the commercial solutions, they extracted eleven different major features for FMISs: Field operations management, Best practice, Finance, Inventory, Traceability, Reporting, Site-specific, Sales, Machinery management, Human resource management, and Quality assurance.

The second and third related scientific papers are the studies conducted by Robbemond and Kruize [7, and Allen and Wolfert [4. Robbemond and Kruize [7] present the functionalities from multiple FMISs. The primary goal of this research was to gain insight into the data standards used in FMISs. This study identified 264 farm management applications coming from 143 different software vendors. This study identified the following eleven major features: Procurement, Inventory management, Product Management, Marketing and sales, Human resource management, Technology management, Energy management, Real estate management, Quality assurance, Finance, and Accounting. A similar review was done by Allen and Wolfert [4 covering only the livestock domain. They describe the current farm ICT tools in this domain, but in fact these tools are FMISs with sometimes restricted functionalities. The study states that interconnectivity of tools and Internet speeds are bottlenecks for the adoption of FMIS. This report identified 127 tools, available for New Zealand farmers, and divided them into the following seven categories: Feed management, Financial management, Labour management, Nutrient management, Resource management, Stock management, and Strategic planning.

The third relevant review publication is a website that presents 156 farm management software packages. Capterra.com [8] filters the different packages based on the following thirteen functionalities: Barcoding / RFID, Contract management, Crop management, Customer management, Financial management, Greenhouse management, Inventory management, Labor management, Livestock management, Order processing, Pricing management, Supplier management, and Traceability.

Besides the above studies, there is a secondary study on the information management of farms by Lawson et al. 9]. This study presents the results of a survey on the perception of farmers on advanced information systems and advanced farming systems in four European countries. In a survey, they asked farmers: "Is the use of possible computer documentation helpful for dealing with government agencies, landlords, consumers etcetera?". A little

75 over $20 \%$ of the farmers answered affirmatively, but the majority of the farmers was unsure. They, however, state that large farms are among the early adopters of precision farming practices. 
The related work identified multiple functionalities of FMISs, but none is based on a systematic literature review. The primary motivation for this SLR is, therefore, the lack of a systematic review of FMISs.

\section{Review protocol}

80

The guidelines for the SLR used in this report are the guidelines from Kitchenham et al. (2009) [6. The guidelines of Kitchenham et al. are adopted from SLR guidelines used in medical literature and adapted for software engineering. For our SLR we defined a protocol shown in Figure 1 adapting the protocol used by Gurbuz \& Tekinerdogan and Köksal \& Tekinerdogan $([10$, ,11]) which are also based on Kitchenham et al. (2009) [6]. Kitchenham et al. 6] defines an SLR as "a means of identifying, evaluating and interpreting all available research relevant to a particular research question, or topic area, or phenomenon of interest." The first step was the identification of research questions, which lead to the search strategy and resulting search strings in the second step. The definition of the search strategy included the selection of search strings and the sources where to search. The definition of the search strategy was an iterative process, where the output of one search string was used to adjust the subsequent search string. In step three we defined the criteria on which we selected the studies. In the fourth step, we applied the criteria to the search results. After this step, we got the articles that we used for a thorough assessment. This assessment was done based on a quality assessment method. In the fifth step, we started with a data extraction form that allowed useful data extraction from the selected papers. The third, fourth and fifth step were iterative. Finally, in the sixth step, we defined methods for data synthesis and presentation of the data. 


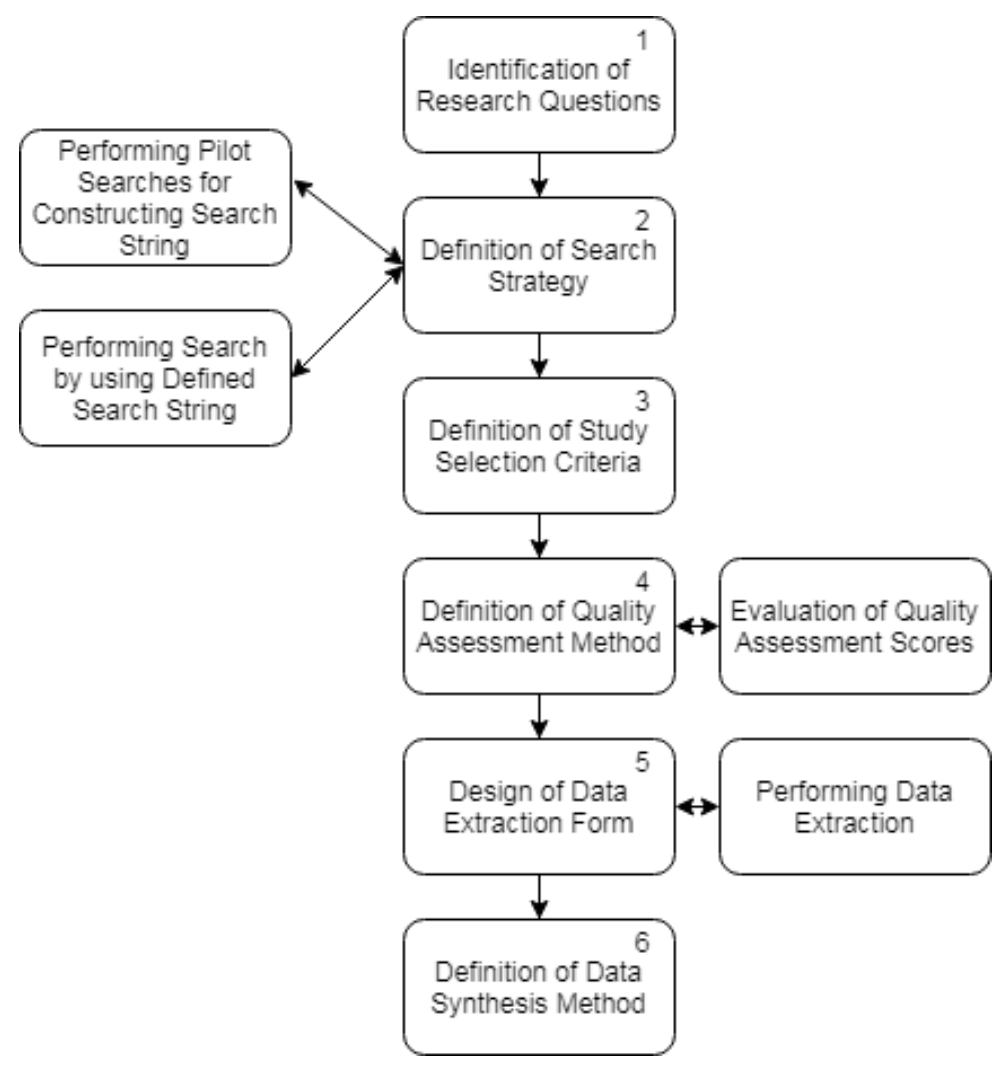

Figure 1: Review protocol for our SLR. Adapted from [10] and [1]

\subsection{Research questions}

From the objective of this research we derived the following three research question to which the SLR should provide answers:

- RQ1: What are the current FMISs described in the literature?

- RQ1.1: Which domains are supported?

- RQ1.2: Which modeling approaches are applied?

- RQ1.3: What are the delivery models?

- RQ1.4: Who are the identified stakeholders?

- RQ2: What are the features of existing FMISs?

- RQ3: What are the obstacles to existing FMISs? 
These research questions are answered using primary studies that were selected by our thorough quality assessment method. The first research question is answered by identifying FMISs described in the studies. For the first subquestion of question one, we looked at which domains of the agricultural sector FMISs were applied (e.g. Livestock, Arable farming). For the second sub-question we checked if the modeling approach is described and if there are diagrams that represent the software architecture. The diagrams can follow informal (boxes-and-lines) or formal (UML or comparable notation) modeling methods [12. For the third sub-question we describe the delivery model as a combination of the software type, the FMIS type, and the software license. First, the software type is described based on the distinction between applications and platforms. Second, the FMIS type is a web-, mobile-, or desktop FMIS. Third, the software license is described, it can be developed by academic researchers (academic) or by a company (commercial). The stakeholders, that we identified in the fourth sub-question, are defined as the persons or groups of persons mentioned in the primary studies. The second research question is addressed by listing the features sorted by the frequency with which they were mentioned. For the third research question, we identified the obstacles mentioned in the primary studies.

\subsection{Search strategy}

To be able to answer the research questions presented in the previous sub-section we performed a systematic search through the available literature in the following digital libraries that publish high-quality papers: IEEE Xplore, ACM Digital Library, Wiley Interscience, Science Direct, Springer, and ISI Web of Knowledge. This selection is based on the sources used in other SLRs, such as [10] and [11. Agricultural software is a fast developing research topic and therefore results from more than a decade ago will probably not be relevant anymore. Therefore, literature from the past eleven years (from 2008 to 2018) was used in this study. The targeted sources of papers were; journal papers, conference papers, workshop papers, and white papers. To find as many relevant results as possible, both an automated and a manual search were performed. The automated search was performed with the help of search strings in the previously stated sources. A manual search was performed by manually browsing the reference list of the papers that were discovered by the automated search (snowballing). For each source, the search string had a different syntax but in general, came down to the following query:

"(Farm OR Agri*) AND (Manage* OR Information) AND (Software OR System* OR Tool OR Platform)"

The results of the search query are listed in column $a$ of Table 3 . The source with the most studies was ISI Web of Knowledge with 422 studies, and the source with the smallest number of studies was ACM digital library with 108 studies. In total 1028 papers were identified via the automated search and 20 papers were added via manual search. 


\subsection{Study selection criteria}

The search string had a broad scope intentionally because we did not want to miss any potentially interesting research. This broad scope has led to a large number of papers, from which we filtered the most relevant ones using the selection criteria presented in Table 1. The selection criteria were applied manually first by reading the title and abstract of the study; which brought down the number of papers to 78 (column $b$, Table 3 ), including the papers found by the manual search. Secondly, we retrieved and read the complete article and applied the selection criteria, which brought down the number of papers to 43.

\begin{tabular}{l|l} 
No. & Criterion \\
\hline EC1 & Papers without full text available \\
\hline EC2 & Papers not written in English \\
\hline EC3 & Duplicate publication from multiple sources \\
\hline EC4 & Papers do not relate to the agricultural sector \\
\hline EC5 & Papers do not relate to management information systems \\
\hline EC6 & Papers do not validate the proposed study \\
\hline EC7 & Papers which are experience and survey papers \\
& Table 1: Study selection criteria
\end{tabular}

\subsection{Study quality assessment}

The 43 included studies were subsequently assessed for quality. Quality assessment was done by reading them entirely and applying the quality criteria presented in Table 2. These criteria are an adaptation of the criteria presented in Kitchenham et al. (2009) [ 6 and from similar SLRs. We chose the criteria based on their influence on the quality of the final product. Points were given to each of the eight criteria based on the following scale: yes=1, somewhat $=0.5$, no $=0$. For example, a full point was given for Q1 if the aim of the study was stated clearly in the introduction (expected place), and no point (0) was given if the aim of the study was not stated in the article. A half point (0.5) was given if the aim was vaguely stated, or not at the expected place. 


\begin{tabular}{l|l} 
No. & Question \\
\hline Q1 & Are the aims of the study clearly stated? \\
\hline Q2 & Are the scope and context and experimental design of the study clearly defined? \\
\hline Q3 & Are the variables in the study likely to be valid and reliable? \\
\hline Q4 & Is the research process documented adequately? \\
\hline Q5 & Are all the study questions answered? \\
\hline Q6 & Are the negative findings presented? \\
\hline Q7 & Are the main findings stated clearly? regarding creditability, validity, and reliability? \\
\hline Q8 & Do the conclusions relate to the aim of purpose of the study? Reliable?
\end{tabular}

Table 2: Quality Assessment Criteria

We decided to exclude studies with a score lower than four points out of eight, to maintain a high-quality input of primary studies for this secondary study. We, therefore, excluded five studies with a score of less than four points and therefore had a total number of 38 studies, to which we refer as the primary studies (column $c$, Table 3). The quality assessment scores for the included 43 studies can be found in Figure 2 


\section{Quality assessment scores versus number of studies}

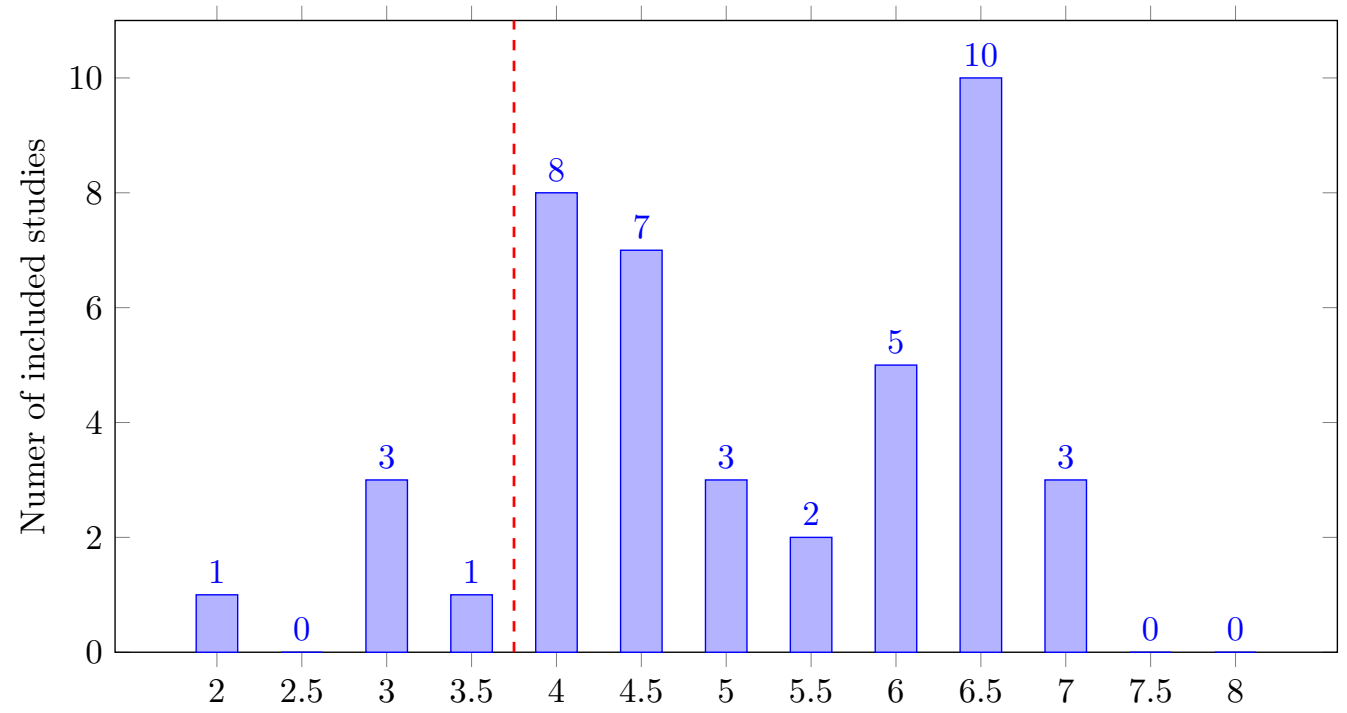

Figure 2: The quality score distribution for the 43 studies after applying the study selection criteria. The studies on the left of the red dashed line are excluded from the results due to their low quality.

\begin{tabular}{l|l|l|l} 
Source & $\begin{array}{l}\text { After automated } \\
\text { and manual search }\end{array}$ & $\begin{array}{l}\text { After applying se- } \\
\text { lection criteria }\end{array}$ & $\begin{array}{l}\text { After reading complete study } \\
\text { and quality assessment }\end{array}$ \\
\hline IEEE Xplore & 111 & 20 & 7 \\
ACM Digital Library & 102 & 10 & 5 \\
Wiley Interscience & 120 & 1 & 0 \\
Science Direct & 138 & 7 & 6 \\
Springer & 135 & 6 & 1 \\
ISI Web of Knowledge & 422 & 14 & 7 \\
Manual search & 20 & 20 & 12 \\
\hline Total & 1048 & 78 & 38
\end{tabular}

Table 3: Overview of search results and study selection 
We read the 38 primary studies and extracted the required data for our analysis with the help of our data extraction form. To make the data extraction form we first read three randomly selected articles and defined the data extraction form based on these papers. Afterwards, we used the data extraction form on five other, randomly selected, studies and extracted the data. After multiple iterations, we came to the data extraction form available in Appendix A. This form contains 28 elements, which includes basic information such as title, publication year and authors and specific information about software characteristics, such as the software license. It also contains elements needed for answering the research questions like the name of the FMIS, the architectural model used, the obstacles identified and the features identified of FMISs. At the end of this form, there is room for notes and the quality assessment. The resulting data from this form is further analyzed in MS Excel to find possible trends. We identified 71 stakeholders, 122 obstacles, and 401 features with the help of the form.

\subsection{Data synthesis}

The data synthesis is the synthesis of the information that we can derive from the data obtained by the data extraction from step five (see Figure 1. All studies name their domains, obstacles, stakeholders, and features with slightly different names. We started by synthesizing synonyms. To be able to discover a trend in the data we identified umbrella concepts that can group all these variations. For the domain, we went from ten different domains to eight domains. For the stakeholders, we went from 71 different stakeholder names to 22 different names. We went down from 122 different names for the obstacles to 53 different names. From the total of 401 identified features, we came to a total of 81 features after synthesis. 


\section{Results}

175 In this section, we first discuss relevant statistics about the 38 primary studies. In the second part of the section, we present the results corresponding to the three research questions.

\subsection{Main statistics}

The 38 primary studies that were included in this research are listed in Table 4 . The publication year of these studies ranges from the years 2008 till 2017. The year-wise distribution can be seen in Figure 3 By far the most popular publication channel is "Computers and Electronics in Agriculture" with 12 primary studies. The second most popular publication channel is "Precision agriculture ('13 \& '15) with two primary studies. ISI Web of Knowledge and IEEE Xplore were the most popular sources for the primary studies, with seven studies directly found via these digital libraries.

\begin{tabular}{|c|c|c|c|c|c|}
\hline Zheleva et al. 13 & 2017 & Murakami et al. 14] & 2013 & Paraforos et al. 15. & 2016 \\
\hline Hewage et al. 16 . & 2017 & Burlacu et al. 17] & 2013 & Sørensen et al. 3] & 2010 \\
\hline Kjær [18] & 2008 & Jiang and Zhang 19] & 2013 & Novkovic et al. 20] & 2015 \\
\hline Khaydarov et al. [21] & 2012 & Yan-e 22] & 2012 & Robbemond and Kruize [7] & 2011 \\
\hline Honda et al. 23. & 2014 & Yu and Yongjun [24] & 2010 & Bligaard 25] & 2014 \\
\hline López-Riquelme et al. 26 & 2017 & Paraforos et al. 27] & 2017 & Cojocaru et al. 28] & 2014 \\
\hline Kruize et al. 29] & 2016 & Fountas et al. [2] & 2015 & Ampatzidis et al. 30 & 2016 \\
\hline Barmpounakis et al. 31 & 2015 & Kaloxylos et al. 32 & 2014 & Fountas et al. 33 & 2015 \\
\hline Carli and Canavari 34 & 2013 & Berger and Hovav 35] & 2013 & Magne et al. 36] & 2010 \\
\hline Voulodimos et al. 37 & 2010 & Kaloxylos et al. 38. & 2012 & Allen and Wolfert 4 & 2011 \\
\hline Li et al. 39. & 2010 & Sørensen et al. 40 . & 2011 & Tsiropoulos and Fountas 41] & 2015 \\
\hline Chen et al. 42 & 2016 & Nikkilä et al. 43 & 2010 & Tsiropoulos et al. 44 & 2013 \\
\hline Bojan et al. 45 & 2015 & Tsiropoulos et al. 46] & 2017 & & \\
\hline
\end{tabular}




\section{Year-wise distribution of primary studies}

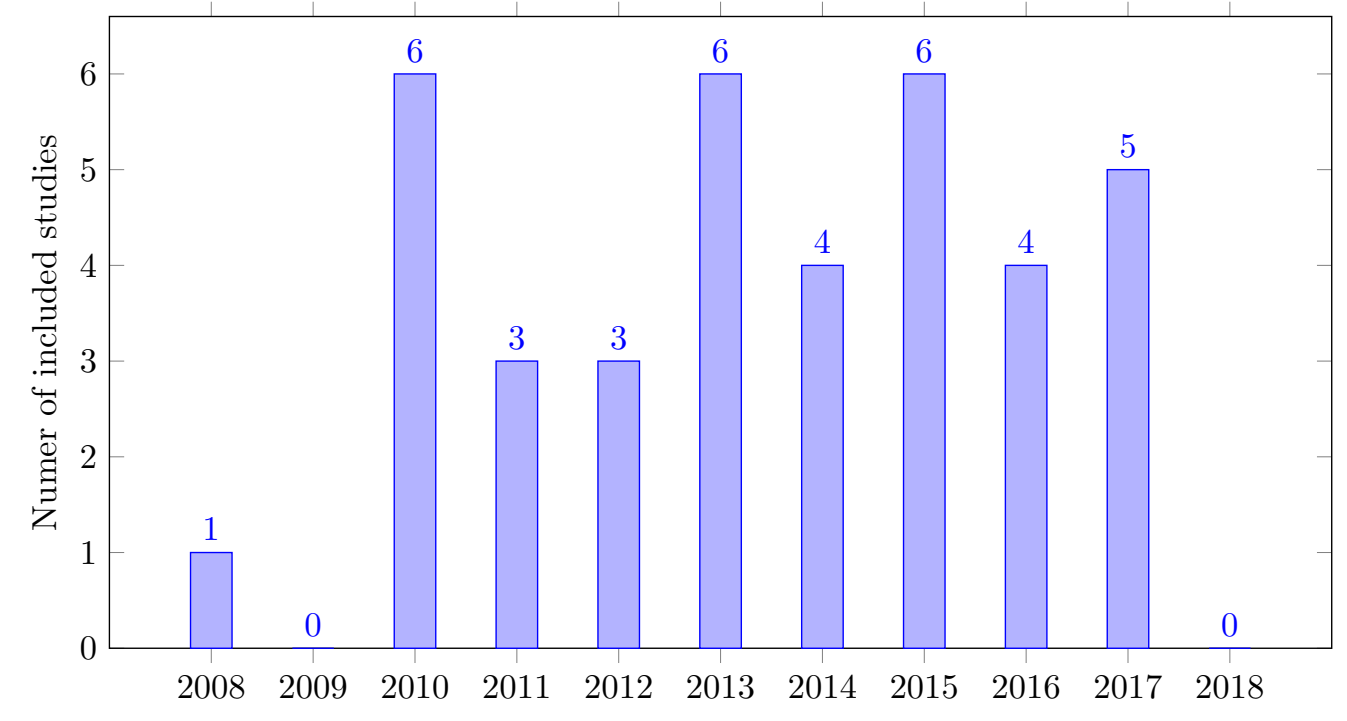

Figure 3: The year-wise distribution for the 38 primary studies.

\subsection{RQ1: What are the current FMISs described in the literature?}

In the primary studies the following FMISs were mentioned: Ifarma, FARMnet, Kilo, Fieldtouch, WIDHOC, FARMA, Ifarm, Afimilk and Mark online. Only one FMIS was described twice: Ifarma, the rest were only described once. Ifarma is a Greek commercial integrated farm management application[15]. Most studies did not name a specific FMIS or had no name for their proposed design. Therefore, the answers to the sub-questions are based on all 38 primary studies, i.e. the ten studies that discussed a named FMIS and the other 28 studies that presented unnamed FMISs.

\subsubsection{RQ1.1: Which domains are supported?}

In Figure 4 the primary studies are divided into five domains that were identified. From this table, it can be seen that the domain that is described the most is Arable farming, with sixteen primary studies. This can be attributed to the fact that the Arable farming domain is ahead regarding the use of precision agriculture practices and the adoption of MIS. The second most described domain with five studies is Livestock. Domains that are mentioned less in the studies are Greenhouse (4), Multipurpose farm (2), and Orchard (2). Nine studies did not specify a specific domain and described one or multiple FMIS(s) that could not be traced back to one domain. Interestingly we did not identify any FMIS for the Forestry or Fishing and Aquaculture domain [4]. 


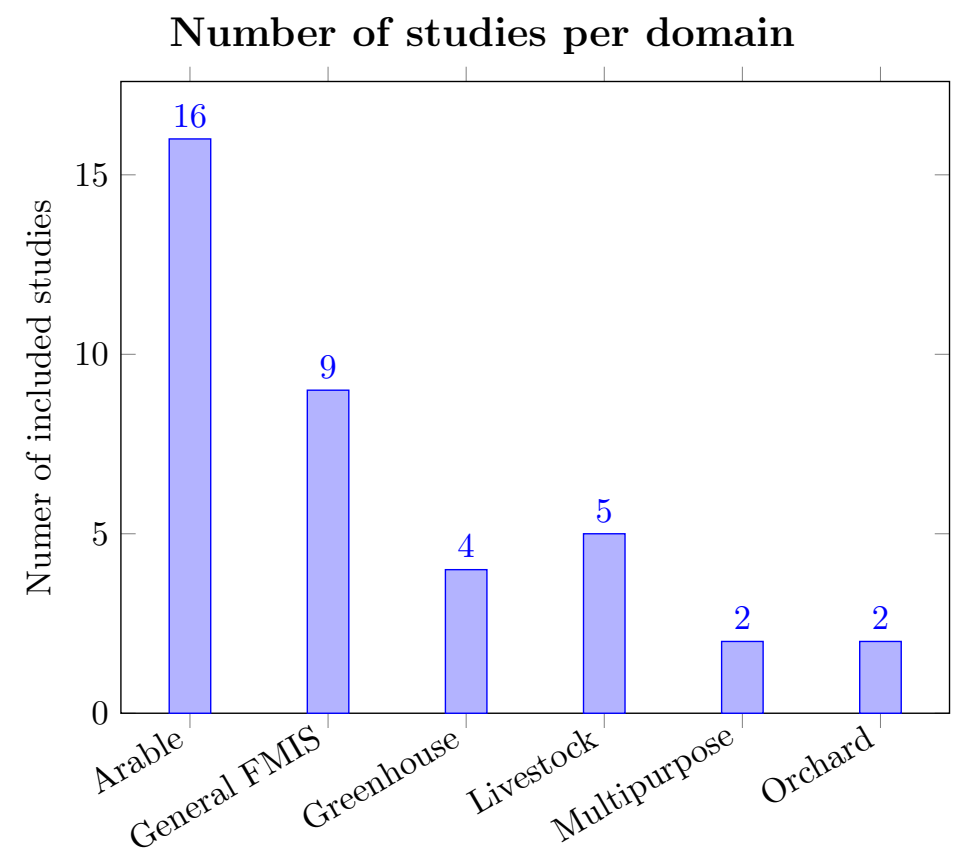

Figure 4: Number of included studies coming from a specific domain. The category "General FMIS" includes the studies that could not be traced back to one domain.

\subsubsection{RQ1.2: Which modeling approaches are applied?}

Software modeling is needed to support the communication between different stakeholders involved in the development of software. There are multiple software modeling notations; the modeling notation can be straightforward with just simple boxes-and-lines, or by following the more complicated Unified Modeling Language (UML) [12]. UML is the de facto industry standard used for making object-oriented analyses and designs for information systems 48. Other methods for modeling are entity-relationship (E-R) and data flow diagrams. The E-R diagram is a basis for representing a unified view of the data model [49] and shows the data layer of a system, the Data flow diagram is a visual tool to depict logic models and expresses data transformation in a system [50]. 


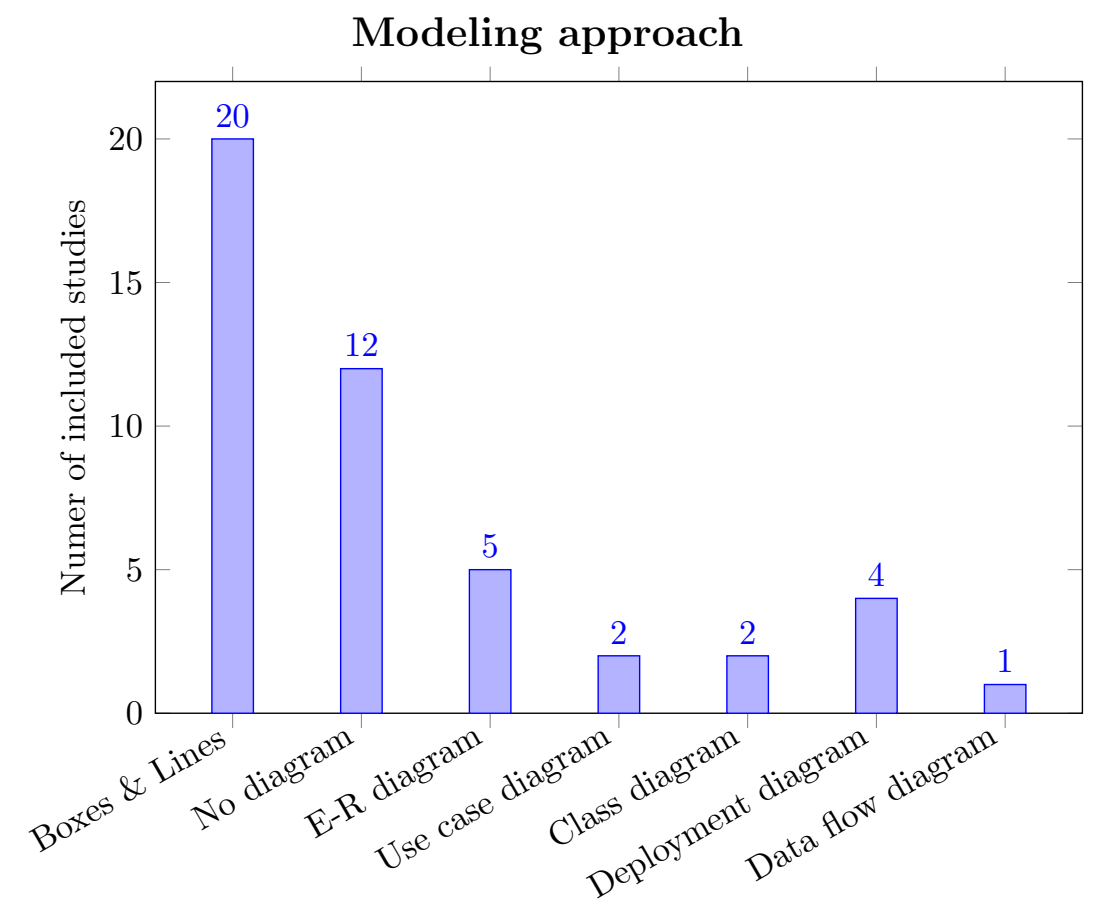

Figure 5: The used modeling approach for the 38 primary studies. A study can describe zero (No Diagram), one, or multiple modeling approaches.

Multiple primary studies describe the software architecture of the FMIS software with models. Figure 5 shows that the boxes-and-lines description occurs 20 times while 12 studies do not have any architectural model at all. The E-R diagram is presented five times in the primary studies, The use case diagram (2 times), class diagram (2 times), and deployment diagram (4 times) are the UML diagrams that appear in the primary studies. Where the use case diagram visualizes use cases and their actors, the class diagram describes the types of objects in the system and the various kinds of static relationships that exist among them, and the deployment diagram shows the physical relationships among software and hardware components in the delivered system 48. The Data flow diagram is only identified once.

Multiple studies use more than one modeling approach. Table 5 shows the modeling approaches used by each primary study. for instance, a Deployment diagram and Use case diagram are used within one study, and a Data flow diagram and an E-R diagram are shown within one study. However, no study uses more than two models, and the 14 more complex models are coming from 10 studies. 


\begin{tabular}{|c|c|}
\hline Model Description & Studies \\
\hline Boxes \& Lines & $\begin{array}{l}\text { Zheleva et al. [13, Kjær [18], 21], Honda et al. [23, López-Riquelme et al. [26], } \\
\text { Voulodimos et al. [37], Chen et al. [42], Bojan et al. [45], Burlacu et al. [17, } \\
\text { Yan-e [22, Yu and Yongjun [24, Paraforos et al. [27], Kaloxylos et al. [38], } \\
\text { Nikkilä et al. [43], Paraforos et al. [15], Bligaard [25], Cojocaru et al. [28], } \\
\text { Ampatzidis et al. [30, Magne et al. [36, Tsiropoulos and Fountas [41] }\end{array}$ \\
\hline No Diagram & $\begin{array}{l}\text { Hewage et al. [16, Murakami et al. [14, Jiang and Zhang [19], Fountas et al. } \\
\text { [2], Berger and Hovav [35], Sørensen et al. 40], Tsiropoulos et al. [46, Novkovic } \\
\text { et al. [20], Robbemond and Kruize [7], Fountas et al. [33], Allen and Wolfert [4, } \\
\text { Tsiropoulos et al. [44] }\end{array}$ \\
\hline E-R Diagram & $\begin{array}{l}\text { Carli and Canavari [34], Voulodimos et al. [37], Paraforos et al. [27], } \\
\text { Paraforos et al. [15], Tsiropoulos and Fountas [41] }\end{array}$ \\
\hline Use Case Diagram & Barmpounakis et al. [31], Li et al. [39] \\
\hline Class Diagram & Kruize et al. [29], Li et al. [39] \\
\hline Deployment Diagram & $\begin{array}{l}\text { Kruize et al. [29], Barmpounakis et al. [31], Kaloxylos et al. [32], Sørensen } \\
\text { et al. [3] }\end{array}$ \\
\hline Data Flow Diagram & Carli and Canavari 34 \\
\hline
\end{tabular}

Table 5: The primary studies sorted per modeling approach. A study can describe zero (No Diagram), one, or multiple modeling approaches. The bold font indicates studies that present multiple model descriptions 


\subsubsection{RQ1.3: What are the delivery models?}

220 a plug-in architecture that allows users or other companies to write custom controllers or extend its functionality easily [51. An application is defined as a computer program that can directly perform an activity [52] and can be deployed locally and used directly. From Figure 6 we see that the described software type was in most studies (21 out of 38) of the application type and in six studies of the platform type. There were six studies of which we were not able to retrieve the delivery model because it was not explicitly stated or shown in the models. Furthermore, we identified five studies which described multiple FMISs in their work and we could, therefore, not categorize these studies in the application, or platform category. 


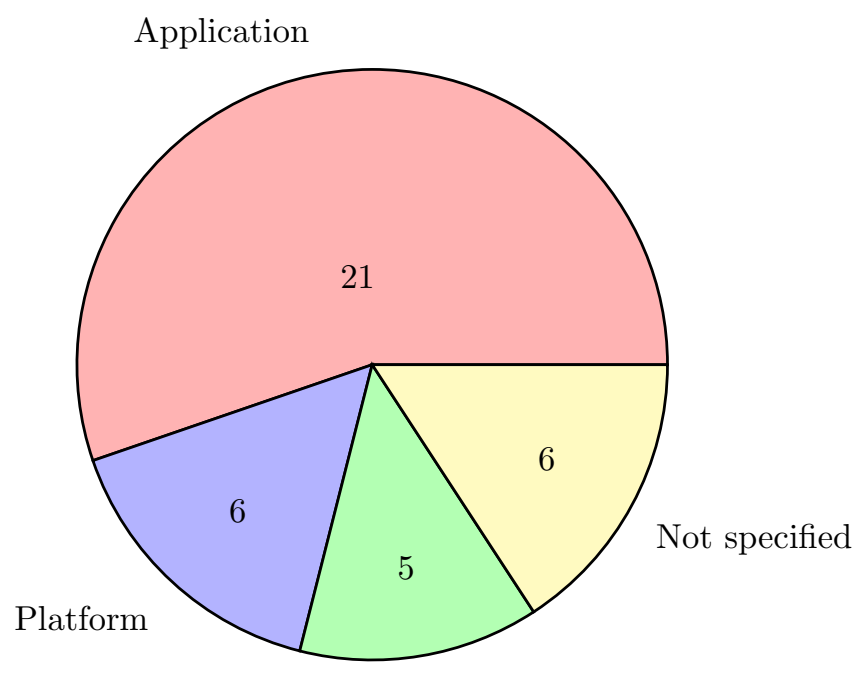

Multiple FMISs

Figure 6: The number of papers describing the software type.

The application and platform structure can again be divided into three FMIS types: The Web FMIS, the Mobile FMIS, and the Desktop FMIS. Where the Desktop FMIS is installed and executed on a desktop or laptop, the mobile FMIS can run entirely on the mobile device, or it can be a web FMIS specialized for a mobile phone [53]. A Web FMIS can be accessed via a browser and can often be accessed via both computers and mobile devices. From our data synthesis method, we also got results for the FMIS types used. The results are presented in Figure 7. From the results, we see that the Web FMIS is described the most, in 21 studies. The Mobile application is described in eleven studies and the Desktop application in five studies. From the figure, we furthermore see that studies describe combinations of the FMIS types and that no standalone Desktop application is described. From six studies we were not able to retrieve the FMIS type since they were not stated explicitly or shown in models. Again five studies present an overview of multiple FMISs and, therefore, we were not able to retrieve the FMIS type of these studies. 


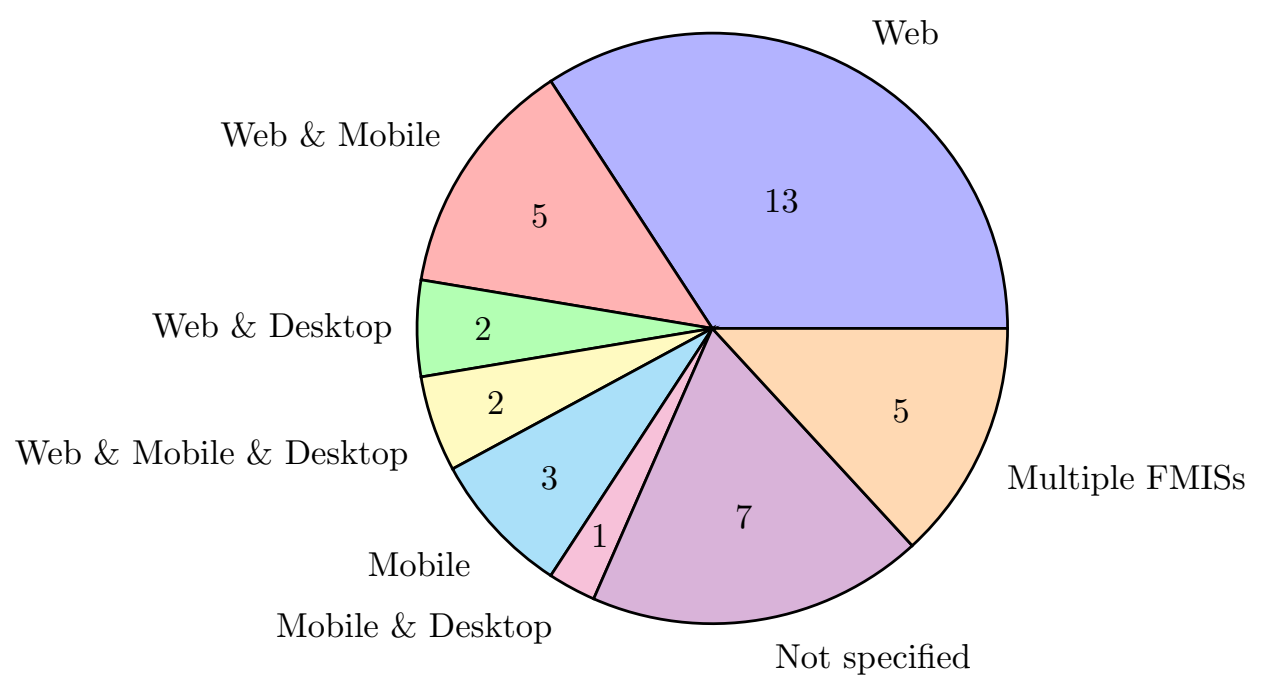

Figure 7: The number of papers describing the FMIS type

The software license of FMISs can be of two types: Academic or Commercial. The Academic license is described as the license for software that is currently under research or has been developed by academic researchers. Commercial software is defined as software developed by a commercial company. In Figure 8 the software licenses from the primary studies are presented. From this Figure, it is seen that fifteen studies described the license as academic. Five studies described a commercial software solution. We also see that 13 studies show a reference design or a reference architecture. These 13 studies present a design only and can therefore not be gathered under the Academic license. We furthermore have five studies that describe multiple FMISs, and we were therefore not able to put the licenses within one parameter. 


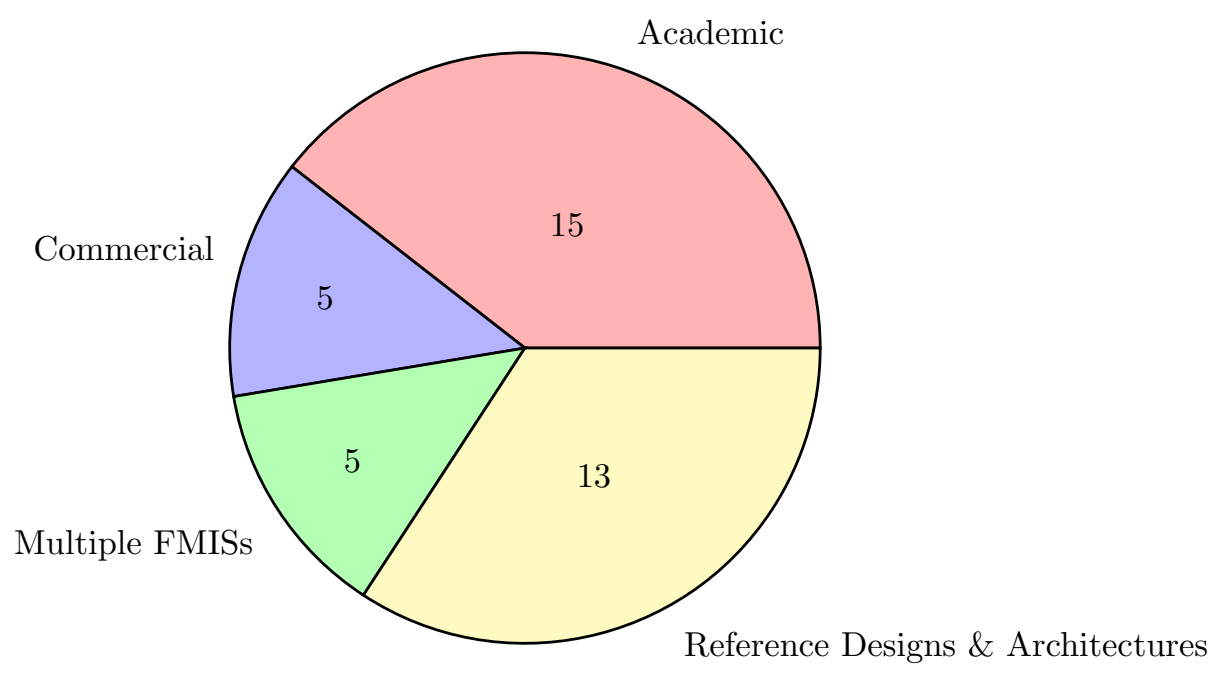

Figure 8: The number of papers describing the software license.

\subsubsection{RQ1.4: Who are the identified stakeholders?}

The Project Management Institute (PMI) defines a stakeholder for a project as follows: "an individual, group, or organization, who may affect, be affected by, or perceive itself to be affected by a decision, activity, or outcome of a project" [54. In total, we identified 22 different stakeholders. They are presented in Table 6 sorted by their

frequency in the primary studies. 


\begin{tabular}{|c|c|c|}
\hline Stakeholder name & Description & \# \\
\hline Farmer & Responsible person on the farm and end-user of the system. & 38 \\
\hline Governmental & $\begin{array}{l}\text { Umbrella term for multiple stakeholders that relate to the government. Has an interest in } \\
\text { FMIS for registration purposes, and to obtain farm information }\end{array}$ & 10 \\
\hline Agricultural expert & $\begin{array}{l}\text { Has expert knowledge about the agricultural sector and can be used for requirements for } \\
\text { FMISs. }\end{array}$ & 7 \\
\hline Farm employee & Works on the farm and has to work with the FMIS. & 6 \\
\hline Research Institute & Multiple kinds of researchers and institutes can be used as knowledge input for FMISs. & 6 \\
\hline FMIS developer & Develops the FMIS and its underlying software. & 5 \\
\hline Input supplier & Delivers inputs to the farm, these inputs can be registered in an FMIS & 5 \\
\hline Agricultural advisor & Helps the farmer with making decisions based on their knowledge, an FMIS can assist them. & 4 \\
\hline $\begin{array}{l}\text { Agriculture service } \\
\text { provider }\end{array}$ & Assists the farmer with the providence of services. Can use FMIS for registration purposes. & 4 \\
\hline Contractor & $\begin{array}{l}\text { Hired by the farmer to perform field tasks. FMISs can improve the communication with the } \\
\text { farmer. }\end{array}$ & 4 \\
\hline Equipment producer & Makes new machinery for the farmer, an FMIS can provide machinery management. & 4 \\
\hline Customer & $\begin{array}{l}\text { Companies and other entities greater than an individual consumer. FMIS can provide details } \\
\text { about the purchased products. }\end{array}$ & 3 \\
\hline Administrator & Can setup system, and manages the FMIS. Is not necessary the FMIS developer. & 2 \\
\hline Farmers association & $\begin{array}{l}\text { Organized group of farmers with common interests. Want FMIS for implementation of } \\
\text { modern technology. }\end{array}$ & 2 \\
\hline Neighbour & Is influenced by decisions of FMIS (Odor nuisance, noise disturbance, etcetera). & 2 \\
\hline Non-governmental & Group of persons with their own (ecological) interest that can be intertwined with the FMIS. & 2 \\
\hline Product processor & FMIS can provide information on products coming from the farm. & 2 \\
\hline Veterinarian & Can use the FMIS for retrieving animal information and can register veterinarian actions. & 2 \\
\hline Accountant & Can use the financial modules of FMISs to verify and assist the farmer with bookkeeping. & 1 \\
\hline Equipment dealer & Can provide machinery support and services via the FMIS. & 1 \\
\hline Media & Provides communication with the outside world and has an influence on the farm image. & 1 \\
\hline $\begin{array}{l}\text { Weather service } \\
\text { provider }\end{array}$ & Provides weather information as input for the FMIS. & 1 \\
\hline
\end{tabular}

Table 6: The identified stakeholders and their relationship to FMISs. 
We also looked at the number of stakeholders types per primary study. The eleven stakeholders that appeared four times or more in the primary studies are shown in Table 7. All primary studies show that the farmer is the primary stakeholders, as expected. The data also shows that the government is the second most mentioned stakeholder. A number of other stakeholders are mentioned for FMISs, for example, Veterinarian, Contractor, and 255 Agricultural advisor. 


\begin{tabular}{|c|c|c|c|c|c|c|c|c|c|c|c|}
\hline \multirow[b]{2}{*}{ Study } & \multicolumn{11}{|c|}{ Stakeholder categories } \\
\hline & S1 & $\mathbf{S 2}$ & S3 & S4 & S5 & S6 & S7 & S8 & S9 & S10 & S11 \\
\hline Kjær 2008 & $\mathrm{X}$ & & & $\mathrm{X}$ & & & & & & & \\
\hline Voulodimos et al. 2010 & $\mathrm{X}$ & & & & & & & & & & \\
\hline Li et al. 2010 & $\mathrm{X}$ & & & & & & & & & & \\
\hline Yu \& Yongjun 2010 & $\mathrm{X}$ & & $\mathrm{X}$ & & & & & & & & \\
\hline Nikkilä et al. 2010 & $\mathrm{X}$ & $\mathrm{X}$ & & & & $\mathrm{X}$ & $\mathrm{X}$ & $\mathrm{X}$ & $\mathrm{X}$ & $\mathrm{X}$ & $\mathrm{X}$ \\
\hline Sørensen et al. 2010 & $\mathrm{X}$ & $\mathrm{X}$ & & & & & $\mathrm{X}$ & & & & $\mathrm{X}$ \\
\hline Magne et al. 2010 & $\mathrm{X}$ & & & & & & & & & & \\
\hline Sørensen et al. 2011 & $\mathrm{X}$ & & & & & & & & & & \\
\hline Robbemond \& Kruize 2011 & $\mathrm{X}$ & & $\mathrm{X}$ & & & $\mathrm{X}$ & & & & & \\
\hline Allen \& Wolfert 2011 & $\mathrm{X}$ & $\mathrm{X}$ & & & $\mathrm{X}$ & & $\mathrm{X}$ & $\mathrm{X}$ & & $\mathrm{X}$ & \\
\hline Khaydarov et al. 2012 & $\mathrm{X}$ & & & & & & & & & & \\
\hline Yan-e 2012 & $\mathrm{X}$ & $\mathrm{X}$ & $\mathrm{X}$ & & $\mathrm{X}$ & & & & & & \\
\hline Kaloxylos et al. 2012 & $\mathrm{X}$ & $\mathrm{X}$ & $\mathrm{X}$ & & $\mathrm{X}$ & $\mathrm{X}$ & & & & $\mathrm{X}$ & $\mathrm{X}$ \\
\hline Calri \& Canavari 2013 & $\mathrm{X}$ & & & $\mathrm{X}$ & & & & & & & \\
\hline Burlacu et al. 2013 & $\mathrm{X}$ & $\mathrm{X}$ & & & $\mathrm{X}$ & & $\mathrm{X}$ & & & & \\
\hline Jiang \& Zhang 2013 & $\mathrm{X}$ & & & & & & & & & & \\
\hline Berger \& Hovav 2013 & $\mathrm{X}$ & & & & & & & & & & \\
\hline Tsiropoulos et al. 2013 & $\mathrm{X}$ & & & & & & & & & & \\
\hline Murakami et al. 2013 & $\mathrm{X}$ & & & & & & & & & & \\
\hline Honda et al. 2014 & $\mathrm{X}$ & & & & & & & & & & \\
\hline Kaloxylos et al. 2014 & $\mathrm{X}$ & & $\mathrm{X}$ & & & & & & $\mathrm{X}$ & & \\
\hline Bligaard 2014 & $\mathrm{X}$ & & & $\mathrm{X}$ & & & & $\mathrm{X}$ & & & \\
\hline Cojocaru et al. 2014 & $\mathrm{X}$ & $\mathrm{X}$ & & & $\mathrm{X}$ & & $\mathrm{X}$ & & & & \\
\hline Barmpounakis et al. 2015 & $\mathrm{X}$ & $\mathrm{X}$ & $\mathrm{X}$ & & & $\mathrm{X}$ & & $\mathrm{X}$ & & & \\
\hline Bojan et al. 2015 & $\mathrm{X}$ & & & & & & & & & & \\
\hline Fountas et al. 2015a & $\mathrm{X}$ & $\mathrm{X}$ & & & & & & & $\mathrm{X}$ & & $\mathrm{X}$ \\
\hline Novkovic et al. 2015 & $\mathrm{X}$ & & & & & & & & & & \\
\hline Fountas et al. 2015b & $\mathrm{X}$ & & & $\mathrm{X}$ & & & & & & & \\
\hline Tsiropoulos \& Fountas 2015 & $\mathrm{X}$ & & & & & & & & & & \\
\hline Kruize et al. 2016 & $\mathrm{X}$ & & & & & $\mathrm{X}$ & & & $\mathrm{X}$ & $\mathrm{X}$ & \\
\hline Chen et al. 2016 & $\mathrm{X}$ & & & & & & & & & & \\
\hline Parafaros et al. 2016 & $\mathrm{X}$ & & & & & & & & & & \\
\hline Ampatzidis et al. 2016 & $\mathrm{X}$ & & & $\mathrm{X}$ & & & & & & & \\
\hline Hewage et al. 2017 & $\mathrm{X}$ & & & & & & & & & & \\
\hline López-Riquelme et al. 2017 & $\mathrm{X}$ & & $\mathrm{X}$ & & & & & & & & \\
\hline Parafaros et al. 2017 & $\mathrm{X}$ & & & & & & & & & & \\
\hline Tsiropoulos et al. 2017 & $\mathrm{X}$ & $\mathrm{X}$ & & $\mathrm{X}$ & $\mathrm{X}$ & & & & & & \\
\hline Zheleva et al. 2017 & $\mathrm{X}$ & & & & & & & & & & \\
\hline Total & 38 & 10 & 7 & 6 & 6 & 5 & 5 & 4 & 4 & 4 & 4 \\
\hline
\end{tabular}

\begin{tabular}{|c|c|}
\hline S1 & Farmer \\
\hline S2 & Governmental \\
\hline S3 & $\begin{array}{c}\text { Agricultural } \\
\text { expert }\end{array}$ \\
\hline S4 & Farm employee \\
\hline S5 & $\begin{array}{r}\text { Research } \\
\text { institute }\end{array}$ \\
\hline S6 & FMIS developer \\
\hline S7 & Input supplier \\
\hline S8 & $\begin{array}{c}\text { Agricultural } \\
\text { advisor }\end{array}$ \\
\hline S9 & $\begin{array}{c}\text { Agricultural } \\
\text { service provider }\end{array}$ \\
\hline S10 & Contractor \\
\hline S11 & $\begin{array}{c}\text { Equipment } \\
\text { producer }\end{array}$ \\
\hline
\end{tabular}

Table 7: The stakeholders that are mentioned four times or more in the primary studies. The name of the stakeholder in the table is not necessarily the name of the stakeholder in the primary study due to the data synthesis step mentioned in Section 3.6 


\subsubsection{Characterization of FMISs}

In the previous sub-sections, we have shown the various characteristics of FMISs, which are the domains, the modeling approaches, the software type, the FMIS type, and the software license. In this sub-section, we look at FMIS mentioned by name. We describe these FMISs based on the characteristics that are identified so far. This information is presented in Table 8 the Study ID refers to the studies listed in Table 4 From this table we see that most FMISs have the Application structure, are modeled with boxes and lines, are under an Academic license, and are available as a web application. The most occurring domain is arable farming.

\begin{tabular}{l|llllll}
$\begin{array}{l}\text { Study } \\
\text { ID }\end{array}$ & $\begin{array}{l}\text { Name Of } \\
\text { FMIS }\end{array}$ & Domain & $\begin{array}{l}\text { Modeling } \\
\text { approach }\end{array}$ & $\begin{array}{l}\text { Software } \\
\text { Type }\end{array}$ & FMIS type & $\begin{array}{l}\text { Software } \\
\text { license }\end{array}$ \\
\hline Zheleva et al. [13] & FARMnet & Multipurpose & Box \& Lines & Application & x & Academic \\
\hline Kjær [18] & Kilo & General & Box \& Lines & Application & $\begin{array}{l}\text { Desktop, } \\
\text { Web, Mobile }\end{array}$ & Academic \\
\hline Honda et al. [23] & Fieldtouch & Arable & Box \& Lines & Platform & Web & Academic \\
\hline López-Riquelme et al. [26] & WIDHOC & Arable & Box \& Lines & Application & Web & Commercial \\
\hline Voulodimos et al. [37] & FARMA & Livestock & Box \& Lines & Application & Mobile & Academic \\
\hline Murakami et al. [14] & Ifarm & Arable & No diagram & Application & Web, Mobile & Academic \\
\hline Paraforos et al. $[\mathbf{2 7}]$ \& [15] & Ifarma & Arable & Box \& Lines & Application & Web, Mobile & Commercial \\
\hline Berger and Hovav [35] & Afimilk & Livestock & No diagram & Platform & Desktop, Web & Commercial \\
\hline Bligaard [25] & Mark online & Multipurpose & Box \& Lines & Application & $\begin{array}{l}\text { Desktop, } \\
\text { Commercial }\end{array}$
\end{tabular}




\subsection{RQ2: What are the features of existing FMISs?}

In total we identified 81 different features of FMISs in the 38 primary studies. A table with all 81 features in descending order is presented in Appendix B and the features that occurred seven times or more are further described below based on their explanation given in the primary studies.

- Financial management: Is defined out of the sub-features coming directly from the studies like making a billing plan, financial analysis, financial planning, calculate economic results, and budgeting.

- Reporting: Consists of sub-features coming from the data synthesis like documentation generation, report making, and automation of filling in documents. This feature occurs over multiple domains.

- Data Acquisition: Is described as the collecting of data coming from the farm. Also occurs over multiple domains.

- Operation plan generation: Making a plan about how the farm will be managed regarding its strategy and execution. Occurs over multiple domains and is a very general, broad term.

- Crop management: The selection of crops, getting information from the crops, checking the quality of the crops and more crop related sub-features.

- Resource management: The process of using the companies resources as efficient as possible. This feature is mainly present in studies that describe FMIS in general.

- Equipment management: Includes all sub-features that relate to the equipment on the farm like tractors, implements, and other machinery.

- Field monitoring: Mainly occurs in the domain of arable farming. Consists of sub-features that monitor the farmland status and their parameters.

- Data processing: Occurs over multiple domains. Makes sure raw data is converted into useful information for farmers.

- Fertilization management: Everything that has to do with the fertilization of the fields, like determining the fertilizing frame, making a fertilizing plan and the tracking of fertilizers. Occurs mainly in the arable farming domain.

- Human resource management: The management of labor, its main goal is to improve the performance of the employees.

- Weather service: Includes all sub-features related to the weather; weather forecasting, climate forecasting, and information about the previous weather.

- Data management: Includes all the sub-features that deal with data or are controlling data. 
- Field management: The field operation management and field-specific management.

- Accounting: The recording of transactions and the keeping of financial records.

- Inventory management: The management of the inventory and stock.

The features and their corresponding studies are presented in Table 9. If we have a look at the features, we see that those occurring the most are those that appear over multiple domains, and more domain specific features appear less. We see that the Financial management feature occurs the most, this was expected since this feature is frequently a central part of FMIS. The other frequently appearing features like Reporting, Data acquisition, Operation plan generation, Resource management, Equipment management, and Data processing also occur over multiple domains and play a central role in the FMIS. Since the arable farming is the most dominant domain in our study, we see that features related to this domain, for example Crop management, Field monitoring, and Fertilization management, appear in the list of Table 9 . We furthermore see that there were no studies that describe all of the sixteen most mentioned features. 


\begin{tabular}{|c|c|c|c|c|c|c|c|c|c|c|c|c|c|c|c|c|c|c|}
\hline \multirow[b]{2}{*}{ Study } & \multicolumn{16}{|c|}{ Feature categories } & & \\
\hline & F1 & F2 & F3 & F4 & \begin{tabular}{|l|l|} 
F5 \\
\end{tabular} & \begin{tabular}{|l|l|l} 
F6 & 1 \\
\end{tabular} & F7 & F8 & F9 & \begin{tabular}{|l|l} 
F10 & 1 \\
\end{tabular} & F11 & F12 & F13 & F14 & F15 & F16 & & \\
\hline Kjær 2008 & & & $\mathrm{X}$ & & & & & & & & & & & & & & & \\
\hline \multicolumn{17}{|l|}{\begin{tabular}{|l} 
Voulodimos et al. 2010 \\
\end{tabular}} & & \\
\hline Li et al. 2010 & & & & & $\mathrm{X}$ & & & & & $\mathrm{X}$ & & & $x$ & & & & \multirow{2}{*}{ F1 } & \multirow{2}{*}{$\begin{array}{c}\text { Financial } \\
\text { management }\end{array}$} \\
\hline Yu \& Yongjun 2010 & $\mathrm{X}$ & $\mathrm{X}$ & & & $\mathrm{X}$ & & & & & & & $\mathrm{x}$ & & $x$ & & & & \\
\hline Nikkilä et al. 2010 & $\mathrm{X}$ & & & & & & $\mathrm{X}$ & & & $\mathrm{X}$ & & $x$ & & & $x$ & & \multirow{2}{*}{ F2 } & \multirow{2}{*}{ Reporting } \\
\hline Sørensen et al. 2010 & & $\mathrm{X}$ & $\mathrm{X}$ & $\mathrm{X}$ & & & & & $\mathrm{X}$ & & & & & & & & & \\
\hline \multicolumn{17}{|l|}{ Magne et al. 2010} & \multirow{2}{*}{ F3 } & \multirow{2}{*}{ Data aquisition } \\
\hline Sørensen et al. 2011 & $\mathrm{X}$ & $\mathrm{X}$ & $\mathrm{X}$ & $\mathrm{X}$ & & & $\mathrm{X}$ & $\mathrm{X}$ & $\mathrm{X}$ & $\mathrm{X}$ & & $\mathrm{x}$ & $x$ & & & $\mathrm{x}$ & & \\
\hline Robbemond \& Kruize 2011 & $\mathrm{X}$ & & & & \begin{tabular}{|l|l} 
& \\
\end{tabular} & $\mathrm{X}$ & & & & & $\mathrm{X}$ & & & & $x$ & $x$ & \multirow{2}{*}{ F4 } & \multirow{2}{*}{$\begin{array}{c}\text { Operation plan } \\
\text { generation }\end{array}$} \\
\hline Allen \& Wolfert 2011 & $\mathrm{X}$ & & & & & $\mathrm{X}$ & & & & $\mathrm{X}$ & $\mathrm{X}$ & & & $x$ & & $\mathrm{x}$ & & \\
\hline Khaydarov et al. 2012 & & & & $\mathrm{X}$ & $\mathrm{X}$ & & & & & $\mathrm{X}$ & & & & & & & \multirow{2}{*}{ F5 } & \multirow{2}{*}{$\begin{array}{c}\text { Crop } \\
\text { management }\end{array}$} \\
\hline Yan-e 2012 & $\mathrm{X}$ & & $\mathrm{X}$ & & $\mathrm{X}$ & & & & & & & & & & & & & \\
\hline Kaloxylos et al. 2012 & & & $\mathrm{X}$ & & $\mathrm{X}$ & & $\mathrm{X}$ & & $\mathrm{X}$ & & & $x$ & & & $x$ & & \multirow{2}{*}{ F6 } & \multirow{2}{*}{$\begin{array}{c}\text { Resource } \\
\text { management }\end{array}$} \\
\hline Calri \& Canavari 2013 & $\mathrm{X}$ & $\mathrm{X}$ & $\mathrm{X}$ & & $\mathrm{X}$ & & $\mathrm{X}$ & & $\mathrm{X}$ & & & & & & $x$ & & & \\
\hline Burlacu et al. 2013 & & $\mathrm{X}$ & $\mathrm{X}$ & $\mathrm{X}$ & & $\mathrm{X}$ & & $\mathrm{X}$ & & & & $\mathrm{x}$ & & & & & \multirow{2}{*}{ F7 } & \multirow{2}{*}{$\begin{array}{c}\text { Equipment } \\
\text { management }\end{array}$} \\
\hline Jiang \& Zhang 2013 & & & $\mathrm{X}$ & & & & $\mathrm{X}$ & & & & & & & & & & & \\
\hline \multicolumn{17}{|l|}{ Berger \& Hovav 2013} & & \\
\hline Tsiropoulos et al. 2013 & & & $\mathrm{X}$ & & & & & & $\mathrm{X}$ & & & & $x$ & & & & 18 & Field monitorıng \\
\hline Murakami et al. 2013 & $\mathrm{X}$ & $\mathrm{X}$ & & & & & & & & & & & $x$ & $x$ & $x$ & & F9 & Data processing \\
\hline Honda et al. 2014 & & & & & & & & $\mathrm{X}$ & & $\mathrm{X}$ & & $x$ & & & $x$ & & ry & Data processing \\
\hline Kaloxylos et al. 2014 & & $\mathrm{X}$ & $\mathrm{X}$ & $\mathrm{X}$ & & & & $\mathrm{X}$ & $\mathrm{X}$ & & & $\mathrm{x}$ & & & & & F10 & Fertilization \\
\hline Bligaard 2014 & $\mathrm{X}$ & $\mathrm{X}$ & & $\mathrm{X}$ & & \begin{tabular}{|l|l|l}
$\mathrm{X}$ & 2 \\
\end{tabular} & $\mathrm{X}$ & & & $\mathrm{X}$ & $\mathrm{X}$ & & & $x$ & & & 100 & management \\
\hline Cojocaru et al. 2014 & $\mathrm{X}$ & & $\mathrm{X}$ & $\mathrm{X}$ & & & & $\mathrm{X}$ & & $\mathrm{X}$ & & & & & & & F11 & Human resource \\
\hline Barmpounakis et al. 2015 & & & & & & & & & $\mathrm{X}$ & & & & $x$ & & & & r11 & management \\
\hline Bojan et al. 2015 & & & & & & & & & $\mathrm{X}$ & & & & & & & & F12 & Weather service \\
\hline Fountas et al. 2015a & $\mathrm{X}$ & $\mathrm{X}$ & & & & \begin{tabular}{|l|l|l}
$\mathrm{X}$ & 2 \\
\end{tabular} & $\mathrm{X}$ & & & & $\mathrm{X}$ & & & $x$ & $x$ & $\mathrm{x}$ & r12 & voedtner service \\
\hline Novkovic et al. 2015 & & & & & $\mathrm{X}$ & & & & & & & & & & & & F13 & Data management \\
\hline Fountas et al. 2015b & $\mathrm{X}$ & & & $\mathrm{X}$ & $\mathrm{X}$ & & $\mathrm{X}$ & $\mathrm{X}$ & & & & & & $x$ & & $\mathrm{x}$ & 13 & Data management \\
\hline Tsiropoulos \& Fountas 2015 & $\mathrm{X}$ & $\mathrm{X}$ & $\mathrm{X}$ & $\mathrm{X}$ & & & & & & & & & & & & $\mathrm{x}$ & F14 & Field \\
\hline Kruize et al. 2016 & & & & & & & & & & & & & & & & & & management \\
\hline Chen et al. 2016 & & & & & & & & & & & & & & & & $x$ & F15 & Accounting \\
\hline Parafaros et al. 2016 & $\mathrm{X}$ & & & & & & & $\mathrm{X}$ & & & & & & & & & $r 10$ & Accounting \\
\hline Ampatzidis et al. 2016 & $\mathrm{X}$ & $\mathrm{X}$ & & & & & & & & & & & & & & & F16 & Inventory \\
\hline Hewage et al. 2017 & & $\mathrm{X}$ & $\mathrm{X}$ & & & $\mathrm{X}$ & & & & & & & & & & & r10 & management \\
\hline López-Riquelme et al. 2017 & & $\mathrm{X}$ & & & $\mathrm{X}$ & & & $\mathrm{X}$ & & & & & $x$ & & & & & \\
\hline Parafaros et al. 2017 & $\mathrm{X}$ & & & $\mathrm{X}$ & & $\mathrm{X}$ & & & & $\mathrm{X}$ & $\mathrm{X}$ & & & & & & & \\
\hline Tsiropoulos et al. 2017 & $\mathrm{X}$ & $\mathrm{X}$ & & & & \begin{tabular}{|l|l|l}
$\mathrm{X}$ & 2 \\
\end{tabular} & $\mathrm{X}$ & & & & $\mathrm{X}$ & & & $x$ & & & & \\
\hline Zheleva et al. 2017 & & & & & & $\mathrm{X}$ & & \begin{tabular}{|l|l}
$\mathrm{X}$ & $\mathrm{z}$ \\
\end{tabular} & $\mathrm{X}$ & & $\mathrm{X}$ & & $x$ & & & & & \\
\hline Total & 17 & 14 & 13 & 10 & \begin{tabular}{|l|}
10 \\
\end{tabular} & 9 & 9 & \begin{tabular}{l|l}
9 \\
\end{tabular} & 9 & \begin{tabular}{l|l}
8 & \\
\end{tabular} & 7 & 7 & 7 & 7 & 7 & 7 & & \\
\hline
\end{tabular}

Table 9: The features that occur seven times or more in the primary studies. The name of the feature in the table is not necessarily the name of the feature in the primary study due to the data synthesis step mentioned in Section 3.6 
4.4. RQ3: What are the obstacles to existing FMISs?

In total, we identified 53 obstacles from the primary studies. The obstacles appearing three times or more are described below. The description is based on the definitions given in the primary studies. A table with all 53 obstacles is presented in descending order of frequency occurrence in Appendix C.

- Standardized data formats: Causes problems with the interoperability between different systems and components.

- System integration: FMISs and their components do not integrate with each other easily. Results to problems with interchangeability between applications and platforms.

- Adoption rate of FMIS: The adoption of agricultural innovations has multiple drivers, which can be divided in competitive and contingent factors, socio-demographic factors and financial resources ([55, [56]). The adoption of new technologies in agriculture is rarely instantaneous and multiple factors influence the decision-making processes [57] and can therefore be a result of multiple obstacles.

- Cost of FMIS: Farmers find FMISs too expensive, or they are not able to see the profitability potential of an FMIS.

- Incomplete FMIS: Multiple FMISs are specialized for one specific task on the farm. However, these systems are therefore missing features that will cause the farmer to use multiple FMISs, instead of one FMIS that can provide in all needs.

- Understandability: Current FMISs are not always easy to understand and use for farmers, due to difficult user interfaces or other factors that make them complex.

- Data size: The accumulation of data over the years is seen as a concern

- Connection to internet: Some FMISs are only accessible with an active internet connection; this connection is however not always reliable in more rural areas.

- Insufficient farmer skills: Farmers frequently have a low level of education, and therefore farmers are not always able to obtain the full potential of FMISs.

- Language and regional: Sometimes FMISs are only available in one language. Furthermore, there are big regional differences between countries concerning agricultural practices; FMISs can therefore not always foresee in all farmers needs due to these differences.

- Security: There are currently concerns about the security and privacy of the data that is used in the FMIS.

The obstacles and their corresponding studies are presented in Table 10 . From the primary studies, we see that obstacles relating to the standardized data formats and the subsequent obstacles to system integration are most frequent in the primary studies. Other obstacles that occur frequently are those related to the lower adoption rate 
of FMIS, lack of required skills, language, and understandability of the system. These four obstacles are directly related to the farmer and can probably be solved by making the FMIS easier to understand for farmers and by making the system available in their language. Another frequently mentioned obstacle is the cost of an FMIS; these are often believed to be too high to be profitable. If costs go down obstacles related to the adoption rate of FMISs will most likely also be solved. Obstacles related to missing features, data size, and security of FMIS could probably be addressed by a new design for FMIS. 


\begin{tabular}{|c|c|c|c|c|c|c|c|c|c|c|c|}
\hline \multirow[b]{2}{*}{ Study } & \multicolumn{11}{|c|}{ Obstacle Categories } \\
\hline & 01 & $\mathbf{O 2}$ & $\mathbf{O 3}$ & 04 & 05 & O6 & $\mathbf{O 7}$ & 08 & O9 & $\mathbf{O 1 0}$ & 011 \\
\hline Kjær 2008 & $\mathrm{X}$ & $\mathrm{X}$ & & & & & & & & & \\
\hline \multicolumn{12}{|l|}{\begin{tabular}{|l} 
Voulodimos et al. 2010 \\
\end{tabular}} \\
\hline Li et al. 2010 & & & & $\mathrm{X}$ & & & & & & $\mathrm{X}$ & \\
\hline \multicolumn{12}{|l|}{\begin{tabular}{|l|} 
Yu \& Yongjun 2010 \\
\end{tabular}} \\
\hline Nikkilä et al. 2010 & $\mathrm{X}$ & & $\mathrm{X}$ & & $\mathrm{X}$ & $\mathrm{X}$ & $\mathrm{X}$ & $\mathrm{X}$ & & $\mathrm{X}$ & \\
\hline Sørensen et al. 2010 & & $\mathrm{X}$ & & & & $\mathrm{X}$ & & & & & \\
\hline Magne et al. 2010 & & & & & & $\mathrm{X}$ & & & & & \\
\hline Sørensen et al. 2011 & & $\mathrm{X}$ & & $\mathrm{X}$ & & & & & & & \\
\hline \begin{tabular}{|l|} 
Robbemond \& Kruize 2011 \\
\end{tabular} & & & & & $\mathrm{X}$ & & & & & & \\
\hline Allen \& Wolfert 2011 & & $\mathrm{X}$ & & $\mathrm{X}$ & & & & $\mathrm{X}$ & $\mathrm{X}$ & & $\mathrm{X}$ \\
\hline \multicolumn{12}{|l|}{ Khaydarov et al. 2012} \\
\hline Yan-e 2012 & $\mathrm{X}$ & & $\mathrm{X}$ & & & $\mathrm{X}$ & & & & & \\
\hline Kaloxylos et al. 2012 & & & & & & & & & & & $\mathrm{X}$ \\
\hline \multicolumn{12}{|l|}{ Calri \& Canavari 2013} \\
\hline Burlacu et al. 2013 & & $\mathrm{X}$ & $\mathrm{X}$ & & & & & & & & \\
\hline \multicolumn{12}{|l|}{ Jiang \& Zhang 2013} \\
\hline Berger \& Hovav 2013 & & & $\mathrm{X}$ & & $\mathrm{X}$ & & & & & & \\
\hline \multicolumn{12}{|l|}{\begin{tabular}{|l|} 
Tsiropoulos et al. 2013 \\
\end{tabular}} \\
\hline Murakami et al. 2013 & & & & $\mathrm{X}$ & & & & & & & \\
\hline \multicolumn{12}{|l|}{ Honda et al. 2014} \\
\hline Kaloxylos et al. 2014 & & & & $\mathrm{X}$ & & & & & $\mathrm{X}$ & & \\
\hline Bligaard 2014 & $\mathrm{X}$ & & & & & & & & & & \\
\hline Cojocaru et al. 2014 & & $\mathrm{X}$ & & & & & & & & & \\
\hline Barmpounakis et al. 2015 & & & & & $\mathrm{X}$ & & & & & & \\
\hline Bojan et al. 2015 & & & & & & & $\mathrm{X}$ & & & & \\
\hline Fountas et al. 2015a & $\mathrm{X}$ & $\mathrm{X}$ & & $\mathrm{X}$ & $\mathrm{X}$ & & $\mathrm{X}$ & & & & \\
\hline \begin{tabular}{|l|} 
Novkovic et al. 2015 \\
\end{tabular} & & & & & & & & & $\mathrm{X}$ & & \\
\hline Fountas et al. 2015b & $\mathrm{X}$ & $\mathrm{X}$ & $\mathrm{X}$ & & & & & & & & \\
\hline \begin{tabular}{|l|l|} 
Tsiropoulos \& Fountas 2015 \\
\end{tabular} & & & $\mathrm{X}$ & & & & & & & & \\
\hline Kruize et al. 2016 & $\mathrm{X}$ & $\mathrm{X}$ & & & & & $\mathrm{X}$ & & & $\mathrm{X}$ & \\
\hline \multicolumn{12}{|l|}{ Chen et al. 2016} \\
\hline \multicolumn{12}{|l|}{ Parafaros et al. 2016} \\
\hline \multicolumn{12}{|l|}{ Ampatzidis et al. 2016} \\
\hline Hewage et al. 2017 & $\mathrm{X}$ & & & & & $\mathrm{X}$ & & & & & \\
\hline López-Riquelme et al. 2017 & $\mathrm{X}$ & & & & & & $\mathrm{X}$ & & & & \\
\hline Parafaros et al. 2017 & & & & & & $\mathrm{X}$ & & & & & \\
\hline Tsiropoulos et al. 2017 & & & $\mathrm{X}$ & & $\mathrm{X}$ & $\mathrm{X}$ & & & & & \\
\hline Zheleva et al. 2017 & & & & $\mathrm{X}$ & $\mathrm{X}$ & & & $\mathrm{X}$ & & & $\mathrm{X}$ \\
\hline Total & 9 & 9 & 7 & 7 & 7 & 7 & 5 & 3 & 3 & 3 & 3 \\
\hline
\end{tabular}

\begin{tabular}{|c|c|}
\hline 01 & $\begin{array}{c}\text { Standardized data } \\
\text { formats }\end{array}$ \\
\hline O2 & System Integration \\
\hline $\mathbf{O 3}$ & $\begin{array}{c}\text { Adoption rate of } \\
\text { FMIS }\end{array}$ \\
\hline 04 & Cost of FMIS \\
\hline 05 & Incomplete FMIS \\
\hline O6 & Understandability \\
\hline 07 & Data size \\
\hline O8 & $\begin{array}{c}\text { Connection to } \\
\text { internet }\end{array}$ \\
\hline O9 & $\begin{array}{c}\text { Insufficient farmer } \\
\text { skills }\end{array}$ \\
\hline 010 & $\begin{array}{c}\text { Language and } \\
\text { regional }\end{array}$ \\
\hline 011 & Security \\
\hline
\end{tabular}

Table 10: The obstacles that occur three times or more in the primary studies. The name of the obstacle in the table is not necessarily the name of the obstacle in the primary study due to the data synthesis step mentioned in Section 3.6

\section{Discussion}

In the following sub-sections, we discuss the results. In Section 5.1 we provide a critical reflection on the results. In Section 5.2 we discuss the results in relation to the related work and in Section 5.3 we discuss the threats to 345 validity of the present study and how we tried to address them. 


\subsection{Critical reflection on the results}

To the best of our knowledge, this study represents the first systematic literature search on FMISs and thereby aims to pave the way for similar studies on FMISs. In this respect, we identified more than one thousand papers from which we identified 38 high quality primary studies. From the results, we can identify several interesting observations. Over the past eight years a stable number of high quality papers have been published on the features and obstacles of FMIS (see Figure 3), whereby the focus has been on arable farming or general purpose FMIS (i.e., not focusing on any specific agricultural domain, see Figure 4). The fact that we were not able to identify FMISs for agricultural domains other than the five we identified might indicate that these domains are not explicitly described in the literature. Although there seems to be a large interest in presenting the architectural designs of FMISs, most of the presented architectural designs are described using informal boxes-and-lines drawings (see Figure 5. Table 57. The designs consist of various designs from different perspectives, often referred to as views [5]. In the reviewed literature, we could identify some explicitly described views, such as the data views (using E-R, data flow models), component-and-connector views (using class diagrams) and deployment views (using deployment diagrams). Clements et al. 2010 [58] documents many more relevant architectural views that are relevant for describing FMISs formally. Based on our results we can state that there seems to be an obvious lack of knowledge on the architecture frameworks that have been provided in the software architecture design community.

We also made interesting discoveries about the software delivery methods. Most of the FMISs we reviewed seemed to be web applications while desktop applications were not explicitly named. This might indicate that a shift is happening from the classic desktop application towards web applications. Most of the FMISs seemed to be application software (as opposed to software platforms) with a predefined set of features, which are not easily extensible. Thus, there seemed to be less focus on a generic and reusable platform software enabling the development of a broader set of applications. Given the broader interest in various domains of FMISs, the focus on generic FMIS platforms could be an interesting research direction. Not surprisingly, the frequently identified FMIS stakeholder was the farmer, followed by the governmental stakeholder.

When analyzing various systems usually both common and variant features can be identified. For the identified FMISs we could observe that some features seemed to be common, indicating the similarity of these FMISs. These common features are generally generic MIS features (e.g., financial management, reporting, and data acquisition) and not specifically related to agriculture. Besides these common generic features, we could also identify several features that do not appear in most FMISs and tend to be variant and specific for some FMISs. We could identify fifty-one obstacles among which we described eleven frequently mentioned obstacles in detail. Some obstacles were very obvious, like system integration and cost of FMIS. Other identified obstacles were less obvious, like the low level of understandability of FMISs, and the lack of required skills by the primary user of the FMISs. No study was identified that described all eleven most occurring features. 


\subsection{Relation to the related work} review protocol that is widely accepted and used in the information systems and software engineering community. Based on the SLR protocol, we have searched and identified the FMISs from a broad set of (more than 1000) studies from which we selected 38 primary studies.

Interestingly, our results show that some FMISs that are widely used in practice (e.g., Agworld, FarmWorks or indicates that there is a gap between the FMISs that are widely used in practice and the FMISs that were the focus of research. If we compare the identified FMIS features with the features mentioned in the related work (see Section 2), we observe overlap. Although features are sometimes differently named, we can almost always put the functions of FMISs from the related work into one of our identified features. Only the functions Site specific [2], Quality assurance [2] [7, and Barcoding / RFID [8] could not be captured in any of our identified features since these do not fulfill the concept of a feature as used in this study. For this study, we only used input from the scientific literature. However, if we would have used gray literature (software specifications, web articles, etcetera), we might have had a different result.

\subsection{Addressing Threats to Validity}

The most important threats to the validity of an SLR study are publication and selection bias, data extraction, and classification [59]. The publication bias is the phenomenon that authors are more likely to publish the positive results rather than the negative results of their research [6]. We believe we covered the threat of publication bias by applying the study quality assessment, which allowed for the exclusion of five low quality papers that did not present negative findings. The threat of selection bias was covered by defining the study inclusion/exclusion criteria after screening a selection of the primary studies. All selection criteria were discussed among the co-authors to ensure their quality. The validity of the data extraction is important; this directly influences the result of this study. To validate the extraction process, two other persons also did the data extraction for respectively three and four papers. There were small differences in the extracted data; these differences were used to improve the data extraction form. We identified that the extracted data covered the research questions. However, obstacles and features can have sub-categories which could be seen as individual features or obstacles. The data synthesis was, however, performed as objective as possible with the primary goal of keeping as much distinction between the concepts as possible. If there was some uncertainty about the synthesis, the original article was used as a reference.

With the help of our study selection criteria, we were able to exclude all papers that did not relate to the goal of this study. There is, however, always the chance that interesting papers were missed after applying the exclusion

criteria, but with a total amount of 38 included papers, we believe we have found a reasonable amount of input data for this secondary study. With the measures presented, we believe we have tackled the main threats for this review. 


\section{Conclusion}

In this study, we have systematically searched the scientific literature of the past eleven years to identify the features and obstacles of FMISs. To the best of our knowledge, this is the first SLR of its kind and the first to review obstacles to FMIS. Our choice to adopt an SLR as an instrument to answer our key research questions appeared to be very useful and led us to the important insights that could be of benefit for both practitioners and researchers. We identified that the FMISs consisted of a combination of some features from the 81 identified features, of which the Financial Management and Reporting features were the most dominant. These two most occurring features are interestingly not directly related to agriculture. We furthermore identified that the FMIS faces a big set of obstacles. In total, we identified a set of 53 obstacles, of which the obstacles related to the standardized data formats and system integration were the most occurring obstacles.

This study has led to novel insights into the current literature of FMIS. First of all, we could identify broad interest in reporting about FMISs. We could indeed identify multiple FMISs that cover a broad range of application domains in the agriculture sector. We could identify multiple different features that define the FMISs. However, from our study, it becomes evident that the notion of architecture design and knowledge of modeling information systems can be considered weak. From the majority of the studies we observe that there is a lack of knowledge among FMIS researchers about the current architecture frameworks that distinguish multiple views for representing architectures from various stakeholder concern perspectives. We believe that many concepts and techniques can be adopted from the software architecture domain.

Another important conclusion is that some widely used FMISs are not reported at all in the literature. A more in-depth and systematic study of these commercial FMISs could further enhance the insight in the development of FMIS and the related benefits and obstacles. The obstacles that we identified were not aimed to criticize the existing FMISs but rather to pave the way for further maturation of the FMISs. We believe that the results of this SLR, as such, is interesting for both researchers that research FMISs and practitioners that aim to develop FMISs. Researchers can identify the key research directions, and practitioners can benefit from the results of this study by a thorough knowledge of the potential features and the possible obstacles. Our future work will include the creation of a new reference architecture for FMIS based on the identified features and obstacles from this study. 


\section{Appendices}

\section{A. Data extraction form}

\begin{tabular}{|c|c|c|}
\hline$\#$ & Extraction Element & Contents \\
\hline \multicolumn{3}{|c|}{ General Information } \\
\hline 1 & ID & \\
\hline 2 & Title & \\
\hline 3 & Date of extraction & \\
\hline 4 & Year & \\
\hline 5 & Authors & \\
\hline 6 & Repository & \\
\hline 7 & Type & $\square$ Journal $\square$ Article $\square$ Book Chapter \\
\hline 8 & SLR Category & $\square$ Include $\square$ Exclude \\
\hline \multicolumn{3}{|c|}{ Description } \\
\hline 9 & Targeted Domain & \\
\hline 10 & Motivation for Study & \\
\hline 11 & Main theme of study & \\
\hline 12 & Findings & \\
\hline 13 & Assessment Approach & $\square$ Case study $\square$ Short example $\square$ Experiment \\
\hline 14 & FMIS type & $\square$ Desktop $\square$ Web $\square$ Mobile $\square$ Not specified \\
\hline 15 & Software type & $\square$ Application $\square$ Platform $\square$ Not specified \\
\hline 16 & Name of FMIS & \\
\hline 17 & Software modeling approach? & $\begin{array}{l}\text { No/Yes: } \square \text { Deployment view } \square \text { Decomposition view } \\
\square \text { Other view: } \quad \square \text { Box and lines }\end{array}$ \\
\hline 18 & Software license & $\begin{array}{l}\square \text { Proprietary freeware } \square \text { Commercial } \square \text { Open-source } \\
\square \text { Academic version } \square \text { Reference design }\end{array}$ \\
\hline 19 & Programming language & \\
\hline 20 & Identified Stakeholders & \\
\hline 21 & Used database & \\
\hline 22 & Constraints/limitations & \\
\hline 23 & Evidence Type & $\begin{array}{l}\square \text { Industrial case } \square \text { Academic case } \square \text { Academic experiment } \\
\square \text { Industrial experiment }\end{array}$ \\
\hline 24 & Identified Obstacles & \\
\hline 25 & Identified Features & \\
\hline \multicolumn{3}{|c|}{ Evaluation } \\
\hline 26 & Personal note & \\
\hline 27 & Additional notes & \\
\hline 28 & Quality Assessment & $\begin{array}{llll}\text { Q1: } & \text { Q2: } & \text { Q3: } & \text { Q4: } \\
\text { Q6: } & \text { Q7: } & \text { Q8: } & \text { tot: }\end{array}$ \\
\hline
\end{tabular}

Figure 9: The data extraction form used in this SLR

\section{B. Feature table}




\begin{tabular}{|c|c|c|c|c|}
\hline Financial management & 17 & Expert knowledge & 5 & Transport management \\
\hline Reporting & 14 & Livestock management & 5 & Calibration management \\
\hline Data aquisition & 13 & Sales & 5 & Experience management \\
\hline Operation plan generation & 10 & Harvest management & 4 & Marketing and sales \\
\hline Crop management & 10 & Machinery tracking & 4 & Reproductivity management \\
\hline Resource management & 9 & Pesticide management & 4 & Weighing management \\
\hline Equipment management & 9 & Scheduling & 4 & Best practice \\
\hline Field monitoring & 9 & Work management & 4 & Collect produce information \\
\hline Data processing & 9 & Knowledge management & 4 & Communication \\
\hline Fertilization management & 9 & Legal management & 4 & Condition management \\
\hline Human resource management & 7 & Activity monitoring & 4 & Delivery management \\
\hline Weather service & 7 & Customer management & 4 & Feed management \\
\hline Data management & 7 & Alerting & 4 & Grazing management \\
\hline Field management & 7 & Production monitoring & 3 & Herd management \\
\hline Accounting & 7 & Seed management & 3 & Printing \\
\hline Inventory management & 7 & Yield monitoring & 3 & Real estate management \\
\hline Decision support & 6 & Parameter monitoring & 3 & Remote controlling \\
\hline Operation management & 6 & Data sharing & 2 & Risk analysis \\
\hline Yield estimation & 6 & Driver assistance & 2 & Society management \\
\hline Field mapping & 6 & Energy management & 2 & Supply management \\
\hline GIS management & 6 & Health management & 2 & Task file management \\
\hline Irrigation management & 6 & Information search & 2 & Task supervision \\
\hline Sensor management & 6 & Model production parameters & 2 & Vision planning \\
\hline Traceability & 6 & Performance management & 2 & B2B Collaboration \\
\hline Data transfer & 5 & Scenario simulation & 2 & Company information \\
\hline Data storage & 5 & Strategic planning & 2 & Environmental monitoring \\
\hline Disease management & 5 & Technology management & 2 & Planting management \\
\hline
\end{tabular}




\section{Obstacle table}

\begin{tabular}{|c|c|c|c|c|c|}
\hline Standardized data formats & 9 & No standardized solution & 2 & Lack of interoperability standards & 1 \\
\hline System Integration & 9 & Poor user interface & 2 & Lack of need for farmer & 1 \\
\hline Adaption rate of FMIS & 7 & Scalability & 2 & Large input needed & 1 \\
\hline Cost of FMIS & 7 & Time consumption & 2 & Missing modules & 1 \\
\hline FMIS not complete & 7 & Access to system & 1 & Model integration & 1 \\
\hline Not easy to understand & 7 & Data accuracy & 1 & No expert trust & 1 \\
\hline Data size & 5 & Data availability & 1 & No farmer specific design & 1 \\
\hline Connection to internet & 3 & Data confidentiality & 1 & No modularity & 1 \\
\hline Insufficient farmer skills & 3 & Data correctness & 1 & Not applicable in other context & 1 \\
\hline Language and regional & 3 & Data exchange & 1 & Not service oriented & 1 \\
\hline Security & 3 & Data intensity & 1 & Performance assurance & 1 \\
\hline Availability & 2 & Data is scattered & 1 & Privacy & 1 \\
\hline Complexity of farms & 2 & Data management & 1 & Proprietary system & 1 \\
\hline Data complexity & 2 & Data processing & 1 & Reliability & 1 \\
\hline Data diversity & 2 & Data timeliness & 1 & Slow information updating & 1 \\
\hline Data integration & 2 & Early stage of development & 1 & Too much information & 1 \\
\hline Data integrity & 2 & Knowledge integration & 1 & Too specialized & 1 \\
\hline Different interfaces & 2 & Lack of information standards & 1 & & \\
\hline
\end{tabular}

\section{References}

[1] H. Waston, A. Caroll, R. Mann, Information Systems for Management: a book of readings, Richard d Irwin, 1991.

[2] S. Fountas, G. Carli, C. Sørensen, Z. Tsiropoulos, C. Cavalaris, A. Vatsanidou, B. Liakos, M. Canavari, J. Wiebensohn, B. Tisserye, Farm management information systems: Current situation and future perspectives, Computers and Electronics in Agriculture 115 (2015) 40-50, doi:10.1016/j.compag.2015.05.011.

[3] C. G. Sørensen, S. Fountas, E. Nash, L. Pesonen, D. Bochtis, S. M. Pedersen, B. Basso, S. B. Blackmore, Conceptual model of a future farm management information system, Computers and Electronics in Agriculture 72 (1) (2010) 37-47, doi:10.1016/j.compag.2010.02.003.

[4] J. Allen, J. Wolfert, Farming for the Future: towards better information-based decision-making and communication-Phase I: Australasian stocktake of farm management tools used by farmers and rural pro- 
fessionals. New Zealand Centre of Excellence in Farm Business Management, Palm, Tech. Rep., AgFirst Consultancy/Wageningen University and Research Centre, 2011.

[5] ISO/IEC/IEEE, Life cycle processes -Requirements engineering, Tech. Rep., ISO/IEC/IEEE, 2011.

[6] B. Kitchenham, O. Pearl Brereton, D. Budgen, M. Turner, J. Bailey, S. Linkman, Systematic literature reviews in software engineering - A systematic literature review, Information and Software Technology 51 (1) (2009) 7-15, doi:10.1016/j.infsof.2008.09.009.

[7] R. Robbemond, J. W. Kruize, Data standards used for data-exchange of FMIS (44), Tech. Rep., LEI Wageningen, 2011.

[8] Capterra, Farm Management Software, URL https://www.capterra.com/farm-management-software/, 2018.

[9] L. G. Lawson, S. M. Pedersen, C. G. Sørensen, L. Pesonen, S. Fountas, A. Werner, F. W. Oudshoorn, L. Herold, T. Chatzinikos, I. M. Kirketerp, S. Blackmore, A four nation survey of farm information management and advanced farming systems: A descriptive analysis of survey responses, Computers and Electronics in Agriculture 77 (1) (2011) 7-20, doi:10.1016/j.compag.2011.03.002.

[10] H. G. Gurbuz, B. Tekinerdogan, Model-based testing for software safety: a systematic mapping study, Software Quality Journal 26 (4) (2018) 1327-1372, doi:10.1007/s11219-017-9386-2.

[11] O. Koksal, B. Tekinerdogan, Obstacles in Data Distribution Service Middleware: A Systematic Review, Future Generation Computer Systems 68 (2017) 191-210, doi:10.1016/j.future.2016.09.020.

[12] H. Van Vliet, Software engineering: principles and practice, vol. 3, Wiley New York, ISBN 9780470031469, 1993.

[13] M. Zheleva, P. Bogdanov, D.-S. Zois, W. Xiong, R. Chandra, M. Kimball, Smallholder agriculture in the information age: Limits and opportunities, LIMITS 2017 - Proceedings of the 2017 Workshop on Computing Within Limits (2017) 59-70 doi:10.1145/3080556.3080563

[14] Y. Murakami, S. K. T. Utomo, K. Hosono, T. Umezawa, N. Osawa, IFarm: development of cloud-based system of cultivation management for precision agriculture, in: Consumer Electronics (GCCE), 2013 IEEE 2nd Global Conference on, IEEE, 233-234, doi:10.1109/GCCE.2013.6664809, 2013.

[15] D. S. Paraforos, V. Vassiliadis, D. Kortenbruck, K. Stamkopoulos, V. Ziogas, A. A. Sapounas, H. W. Griepentrog, A Farm Management Information System Using Future Internet Technologies, IFAC-PapersOnLine 49 (16) (2016) 324-329, doi:10.1016/j.ifacol.2016.10.060. 
[16] P. Hewage, M. Anderson, H. Fang, An Agile Farm Management Information System Framework for Precision Agriculture, in: Proceedings of the 9th International Conference on Information Management and Engineering, ACM, 75-80, doi:10.1145/3149572.3149583, 2017.

[17] G. Burlacu, L.-E. Cojocaru, C. Danila, D. Popescu, A. M. Stanescu, A digital business ecosystem integrated approach for farm management information system, in: Systems and Computer Science (ICSCS), 2013 2nd International Conference on, IEEE, 80-85, doi:10.1109/IcConSCS.2013.6632027, 2013.

[18] K. E. Kjær, Designing middleware for context awareness in agriculture, in: Proceedings of the 5th Middleware doctoral symposium, ACM, 19-24, doi:10.1145/1462728.1462732, 2008.

[19] R. Jiang, Y. Zhang, Research of agricultural information service platform based on internet of things, in: 2013 12th International Symposium on Distributed Computing and Applications to Business, Engineering \& Science, IEEE, 176-180, doi:10.1109/DCABES.2013.39, 2013.

[20] N. Novkovic, C. Huseman, T. Zoranovic, B. Mutavdzic, Farm Management Information Systems., in: HAICTA, 705-712, doi:10.5937/ekoPolj1402441H, 2015.

[21] Z. Khaydarov, T. H. Laine, S. Gaiani, J. Choi, C. Lee, Context-aware agriculture organizer, in: Proceedings of the 6th International Conference on Ubiquitous Information Management and Communication, ICUIMC'12, 69, doi:10.1145/2184751.2184835, 2012.

[22] D. Yan-e, Research about based-SOA agriculture management information system, in: Information and Automation (ICIA), 2012 International Conference on, IEEE, 78-82, doi:10.1109/ICInfA.2012.6246786, 2012.

[23] K. Honda, A. V. M. Ines, A. Yui, A. Witayangkurn, R. Chinnachodteeranun, K. Teeravech, Agriculture information service built on geospatial data infrastructure and crop modeling, in: Proceedings of the 2014 international workshop on web intelligence and smart sensing, ACM, 1-9, doi:10.1145/2637064.2637094, 2014.

[24] L. Yu, L. Yongjun, A research and practice for sugarcane area's farm management information service platform, in: Computer Application and System Modeling (ICCASM), 2010 International Conference on, vol. 9, IEEE, V9-218, doi:10.1109/ICCASM.2010.5623050, 2010.

[25] J. Bligaard, Mark Online, a Full Scale GIS-based Danish Farm Management Information System, International Journal on Food System Dynamics 5 (4) (2014) 190-195, doi:10.18461/ijfsd.v5i4.544.

[26] J. A. López-Riquelme, N. Pavón-Pulido, H. Navarro-Hellín, F. Soto-Valles, R. Torres-Sánchez, A software architecture based on FIWARE cloud for Precision Agriculture, Agricultural Water Management 183 (2017) 123-135, doi:10.1016/j.agwat.2016.10.020.

[27] D. S. Paraforos, V. Vassiliadis, D. Kortenbruck, K. Stamkopoulos, V. Ziogas, A. A. Sapounas, H. W. Griepentrog, Multi-level automation of farm management information systems, Computers and Electronics in Agriculture 142 (2017) 504-514, doi:10.1016/j.compag.2017.11.022. 
[28] L.-E. Cojocaru, G. Burlacu, D. Popescu, A. M. Stanescu, Farm Management Information System as Ontological Level in a Digital Business Ecosystem, in: Service Orientation in Holonic and Multi-Agent Manufacturing and Robotics, Springer, 295-309, doi:10.1007/978-3-319-04735-5, 2014.

[29] J. W. Kruize, J. Wolfert, H. Scholten, C. N. Verdouw, A. Kassahun, A. J. Beulens, A reference architecture for Farm Software Ecosystems, Computers and Electronics in Agriculture 125 (2016) 12-28, doi:10.1016/j.compag.

[30] Y. Ampatzidis, L. Tan, R. Haley, M. D. Whiting, Cloud-based harvest management information system for hand-harvested specialty crops, Computers and Electronics in Agriculture 122 (2016) 161-167, doi:10.1016/j. compag.2016.01.032.

[31] S. Barmpounakis, A. Kaloxylos, A. Groumas, L. Katsikas, V. Sarris, K. Dimtsa, F. Fournier, E. Antoniou, N. Alonistioti, S. Wolfert, Management and control applications in Agriculture domain via a Future Internet Business-to-Business platform, Information Processing in Agriculture 2 (1) (2015) 51-63, doi:10.1016/j.inpa. 2015.04.002.

[32] A. Kaloxylos, A. Groumas, V. Sarris, L. Katsikas, P. Magdalinos, E. Antoniou, Z. Politopoulou, S. Wolfert, C. Brewster, R. Eigenmann, C. Maestre Terol, A cloud-based farm management system: Architecture and implementation, Computers and Electronics in Agriculture 100 (2014) 168-179, doi:10.1016/j.compag.2013.11. 014 .

[33] S. Fountas, C. G. Sorensen, Z. Tsiropoulos, C. Cavalaris, V. Liakos, T. Gemtos, Farm machinery management information system, Computers and Electronics in Agriculture 110 (2015) 131-138, doi:10.1016/j.compag.2014. 11.011.

${ }_{535}$ [34] G. Carli, M. Canavari, Introducing direct costing and activity based costing in a farm management system: A conceptual model, Procedia Technology 8 (2013) 397-405, doi:10.1016/j.protcy.2013.11.052.

[35] R. Berger, A. Hovav, Using a Dairy Management Information System to Facilitate Precision Agriculture: The

ㅁ Case of the AfiMilk@ System, Information Systems Management 30 (1) (2013) 21-34, doi:10.1080/10580530. 2013.739885 .

[36] M. A. Magne, M. Cerf, S. Ingrand, A conceptual model of farmers' informational activity: A tool for improved support of livestock farming management, Animal 4 (6) (2010) 842-852, doi:10.1017/S1751731110000637.

[37] A. S. Voulodimos, C. Z. Patrikakis, A. B. Sideridis, V. A. Ntafis, E. M. Xylouri, A complete farm management system based on animal identification using RFID technology, Computers and Electronics in Agriculture 70 (2) (2010) 380-388, doi:10.1016/j.compag.2009.07.009.

[38] A. Kaloxylos, R. Eigenmann, F. Teye, Z. Politopoulou, S. Wolfert, C. Shrank, M. Dillinger, I. Lampropoulou, E. Antoniou, L. Pesonen, H. Nicole, F. Thomas, N. Alonistioti, G. Kormentzas, Farm management systems and 
the Future Internet era, Computers and Electronics in Agriculture 89 (2012) 130-144, doi:10.1016/j.compag. 2012.09 .002 .

[39] M. Li, J. P. Qian, X. T. Yang, C. H. Sun, Z. T. Ji, A PDA-based record-keeping and decision-support system for traceability in cucumber production, Computers and Electronics in Agriculture 70 (1) (2010) 69-77, doi: 10.1016/j.compag.2009.09.009.

[40] C. G. Sørensen, L. Pesonen, D. D. Bochtis, S. G. Vougioukas, P. Suomi, Functional requirements for a future farm management information system, Computers and Electronics in Agriculture 76 (2) (2011) 266-276, doi: 10.1016/j.compag.2011.02.005.

555 [41] Z. Tsiropoulos, S. Fountas, Farm management information system for fruit orchards, in: Precision agriculture'15, Wageningen Academic Publishers, 44-55, doi:10.3920/978-90-8686-814-8, 2015.

[42] P.-J. Chen, Y.-C. Du, K.-A. Cheng, C. Y. Po, Development of a management system with RFID and QR code for matching and breeding in Taiwan pig farm, in: Electrical Engineering/Electronics, Computer, Telecommunications and Information Technology (ECTI-CON), 2016 13th International Conference on, IEEE, 1-5, doi:10.1109/ECTICon.2016.7561394, 2016.

[43] R. Nikkilä, I. Seilonen, K. Koskinen, Software architecture for farm management information systems in precision agriculture, Computers and Electronics in Agriculture 70 (2) (2010) 328-336, doi:10.1016/j.compag.2009. 08.013 .

[44] Z. Tsiropoulos, S. Fountas, T. Gemtos, I. Gravalos, D. Paraforos, Management information system for 565 spatial analysis of tractor-implement draft forces, in: Precision agriculture '13, Springer, 349-356, doi: 10.3920/978-90-8686-778-3, 2013.

[45] V.-C. Bojan, I.-G. Raducu, F. Pop, M. Mocanu, V. Cristea, Cloud-based service for time series analysis and visualisation in farm management system, in: Intelligent Computer Communication and Processing (ICCP), 2015 IEEE International Conference on, IEEE, 425-432, doi:10.1109/ICCP.2015.7312697, 2015.

[46] Z. Tsiropoulos, G. Carli, E. Pignatti, S. Fountas, Future Perspectives of Farm Management Informa-

口 tion Systems, in: Precision Agriculture: Technology and Economic Perspectives, Springer, 181-200, doi: 10.1016/j.compag.2015.05.011, 2017.

[47] Food and Agriculture Organization of the United Nations, Decent Rural Employment, Agricultural sub-sectors, URL http://www . fao.org/rural-employment/agricultural-sub-sectors/en//, 2011.

${ }_{575}$ [48] M. Fowler, C. Kobryn, K. Scott, UML Distilled: A Brief Guide to the Standard Object Modeling Language, Addison-Wesley Professional, ISBN 9780321193681, doi:10.1109/MS.2005.81, 2004.

[49] P. P.-S. Chen, The entity-relationship model, toward a unified view of data, ACM Transactions on Database Systems (TODS) 1 (1) (1976) 9-36, doi:10.1145/320434.320440. 
[50] Q. Li, Y.-L. Chen, Data Flow Diagram, in: Modeling and Analysis of Enterprise and Information Systems, Springer, Berlin, Heidelberg., 85-97, doi:10.1007/978-3-540-89556-5, 2009.

[51] R. Diankov, J. Kuffner, OpenRAVE : A Planning Architecture for Autonomous Robotics, Tech. Rep., Robotics Institute, Pittsburgh, PA, Tech., 2008.

[52] P. E. Ceruzzi, A history of modern computing, MIT press, ISBN 9780262532037, 2003.

[53] A. I. Wasserman, Software engineering issues for mobile application development, in: Proceedings of the FSE/SDP workshop on Future of software engineering research, 397-400, doi:10.1145/1882362.1882443, 2010.

[54] Project Management Institute, A guide to the project management body of knowledge (PMBOK ß guide), Project Management Institute, ISBN 9781628253825, doi:10.1002/pmj.20125, 2013.

[55] E. Pierpaoli, G. Carli, E. Pignatti, M. Canavari, Drivers of precision agriculture technologies adoption: a literature review, Procedia Technology 8 (2013) 61-69, doi:10.1016/j.protcy.2013.11.010.

[56] S. M. Pedersen, K. M. Lind, Adoption and perspectives of auto-guidance in northern Europe, in: Precision agriculture'15, Wageningen Academic Publishers, 64-71, doi:10.3920/978-90-8686-814-8, 2015.

[57] E. Dimara, D. Skuras, Adoption of agricultural innovations as a two-stage partial observability process, Agricultural Economics 28 (3) (2003) 187-196, doi:10.1111/j.1574-0862.2003.tb00137.x.

[58] P. Clements, L. Bass, Using business goals to inform a software architecture, in: Requirements Engineering Conference (RE), 2010 18th IEEE International, IEEE, 69-78, doi:10.1109/RE.2010.18, 2010.

[59] T. Dybå, T. Dingsøyr, Strength of evidence in systematic reviews in software engineering, in: Proceedings of the Second ACM-IEEE international symposium on Empirical software engineering and measurement, ACM, 178-187, doi:10.1145/1414004.1414034, 2008. 